\title{
Flamenco Jazz: An Analytical Study
}

Peter Manuel

Since the 1990s, the hybrid genre of flamenco jazz has emerged as a dynamic and original entity in the realm of jazz, Spanish music, and the world music scene as a whole. Building on inherent compatibilities between jazz and flamenco, a generation of versatile Spanish musicians has synthesized the two genres in a wide variety of forms, creating in the process a coherent new idiom that can be regarded as a sort of mainstream flamenco jazz style. A few of these performers, such as pianist Chano Domínguez and wind player Jorge Pardo, have achieved international acclaim and become luminaries on the Euro-jazz scene. Indeed, flamenco jazz has become something of a minor bandwagon in some circles, with that label often being adopted, with or without rigor, as a commercial rubric to promote various sorts of productions (while conversely, some of the genre's top performers are indifferent to the label $^{1}$ ). Meanwhile, however, as increasing numbers of gifted performers enter the field and cultivate genuine and substantial syntheses of flamenco and jazz, the new genre has come to merit scholarly attention for its inherent vitality, richness, and significance in the broader jazz world.

The Spanish jazz scene has been documented in a handful of publications (e.g., García Martínez 1996), a few authors have written on socio-musical aspects of the flamenco jazz scene (Iglesias 2005; Germán Herrero 1991; Lag-López 2006; Salinas Rodríguez 1994; Steingress 2004), and certain sorts of information regarding leading flamenco jazz performers are of course available on the internet. However, nothing has been published on flamenco jazz in the way of formal analytical studies except for two useful articles by Juan Zagalaz (2012a and 2012b) regarding the early fusion music of Jorge Pardo. The present article does not attempt to provide an ethnography of the flamenco jazz scene nor a historical survey of the genre replete with obligatory names and dates. Rather, it aims to

\footnotetext{
${ }^{1}$ For its part, the very word "jazz" often fares poorly in Castilian Spanish, which accommodates none of the word's three phonemes; with the Andalusian tendency to omit final and preconsonantal sibilants, the word is often pronounced something like "[el] yahh."
} 
illuminate the formal aspects of flamenco jazz, especially in terms of its relation to its two constitutive source genres. Further, while concisely surveying some of the diverse idiosyncratic combinations of the two forms, it devotes special attention to the sort of mainstream form of the genre that has coalesced in recent decades. ${ }^{2}$ As befits an article in a jazz journal, this essay assumes a readership that is familiar with jazz but not necessarily with flamenco.

\section{A HISTORICAL SKETCH: FROM PACO TO CHANO}

As has been often noted (e.g., García n.d.: 31-33), the cultural stagnation of the Franco regime, which lasted from 1939 until the dictator's death in 1975, extended to all aspects of the Spanish music scene, including flamenco, art music, popular music, and jazz. Cultivation of the latter was particularly stunted by the lack of a strong network of conservatories and music schools and by the general ambience of provincialism and xenophobia the dictatorship promoted. From the 1970s, however, the flamenco scene was enlivened by a new generation of gifted performers, especially guitarist Paco de Lucía (1947-2014). De Lucía's innovations and brilliance were multi-faceted. He extended and enriched the technique and forms of traditional flamenco guitar; further, with collaborators, he popularized the idiom of composing tuneful, original songs (especially tangos and rumbas, often rendered with bass and percussion) which became the mainstay of "nuevo flamenco." Most relevant here are his activities which contributed to the surging of flamenco jazz from the late 1980s.

De Lucía's jazz-related undertakings can be grouped into two categories. First were his collaborations with non-Spanish musicians, especially the guitar-trio recordings and concert tours with Larry Coryell and John McLaughlin from 1974, and more extensively from 1979 with Al Di Meola replacing Coryell. In 1982, he also collaborated with pianist Chick Corea, some of whose output, such as the album My Spanish Heart (1976), reflected the pianist's ongoing interest in Spanish-inspired music. Second would be de Lucía's formation of his own sextet-most active in the 1980s—which incorporated jazz players Jorge Pardo (flute, sax) and Carles Benavent (five-string electric bass).

\footnotetext{
${ }^{2}$ A word regarding my own background and methodology may be appropriate. I am an amateur performer of jazz guitar and piano and of flamenco guitar, having studied that idiom in New York and in several trips to Spain. While most of the material in this article derives from my own analyses, I interviewed various Spanish performers and of course availed myself of the assorted interviews with others that are available on YouTube and other digital sources. I am especially grateful to Alex Conde, Pedro Ojesto, Adam del Monte, and Marcos Teira for their perspectives. I also thank jazz scholar Dean Reynolds for piquing my interest in this topic.
} 
It has been customary among some Spanish chroniclers to refer to these productions as jazz-oriented or "jazzistic" and to situate them as landmarks in the emergent genre of flamenco jazz. ${ }^{3}$ Implicit or explicit in such characterizations is a tendency to designate as "jazz" any music played by a small group-such as the Lucía/McLaughlin/Di Meola trio--, foregrounding improvised solos consisting of single-note melodies over chord progressions. I would opine that such assertions exaggerate the presence of jazz in these musical works. Or, to put it differently, and without attempting to advance a canonic definition of "jazz," I would argue that for the purposes of this particular study it is useful to employ a more restricted conception of the genre. Such a definition, while certainly encompassing more than the "mainstream" of jazz standards with familiar ii-V-Ibased harmonies rendered in swing rhythm, nevertheless connotes a certain discernable, coherent, structurally interrelated gamut of harmonies, phrase-types, and stylistic features.

Using such a conception can afford a more nuanced understanding of the innovations of de Lucía and can also serve to contrast his music with the more cohesive mainstream of flamenco jazz that would subsequently coalesce. In general, the music of the guitar trios, and of de Lucía's similar collaborations with McLaughlin, was in some respects a sui generis entity quite distant from either jazz or flamenco (neither McLaughlin nor Di Meola know flamenco, and the latter didn't play jazz). ${ }^{4}$ As de Lucía stated, "In my work with Larry Coryell, John McLaughlin, and Al Di Meola the music wasn't flamenco or jazz, it was a fusion of musicians more than of styles” (in Téllez 2003:355). The trios' repertoire consisted primarily of tunes such as "Mediterranean Sundance" and de Lucía's rumba "Río Ancho," with straightforward diatonic harmonies, or Corea's "Spain," with its passing "Spanish-tinged" VI-V7 cadences, and, later, de Lucía's modern flamenco tunes such as "Ziryab." Over these chord changes, the guitarists would perform the default technique of diatonic, primarily scalar, single-note runs (in flamenco parlance, picado) at machine-gun speed. As de Lucía related, he struggled to learn how to solo over changes, and his improvisations often sounded awkward, but he eventually became comfortable in the art even if his style had little to do with any sort of extant jazz..$^{5}$

\footnotetext{
${ }^{3}$ See, e.g., García n.d.:64; Téllez 2003:358; and Pérez Custodio 2005:103. More detailed, rigorous, and consistent with my own approach is the analysis of Zagalaz op. cit.

${ }^{4}$ Coryell, of course, was a prominent jazz guitarist, although he devoted much of his energy to various eclectic productions. McLaughlin is certainly capable of playing jazz, though his own music, like that of Di Meola, has been more in the nature of idiosyncratic rock fusion.

${ }^{5}$ As he noted, "My music is flamenco... I cannot be a jazz musician. I can't play the notes that well" (in Sevilla 1995:122-23.) While flamenco guitar generally uses picado sparingly-essentially
} 
Nevertheless, the music of de Lucía's sextet, which toured extensively in the 1980s and beyond, had its own sort of relation to jazz. The "combo" formatwith bass and cajón percussion-was, of course, new to flamenco, although it became standard with song-oriented nuevo flamenco. In live performances, the sextet typically presented a sort of variety show, including a guitar solo by de Lucía, together with group items which variously featured a singer, some dancing, renditions of a few popular songs such as "Como el agua" or "Sólo quiero caminar," and, most relevantly, songs such as "Ziryab" and "Chiquito," which contained at least brief solos by de Lucía and Pardo, and perhaps others. As discussed below, the harmonies of the latter songs lie more in the realm of modern flamenco than jazz, although the practice of improvising over chord changes (a rueda de acordes) certainly derived from jazz. De Lucía would solo in his idiosyncratic manner, but the playing of Pardo and Benavent would be clearly in the style of modern jazz, as might be expected from their background as primarily jazz players who took up flamenco upon joining the sextet. Thus, Zagalaz, in his aforementioned studies, focuses on Pardo's introduction of chromatic jazz phrases in his solos.

If de Lucía's innovative activities of the 1970s-80s may bear only a tangential relationship to jazz, his establishment of the practice of soloing, in quasiflamenco style, over chord changes in small group format certainly provided inspiration and legitimization for the more extensive and elaborate fusions of jazz and flamenco that took place from the 1990s onward. A crucial development was the expansion, from the 1980s, of conservatories and music education in general in Spain, which produced a new generation of pianists and others who, with their solid classical and often jazz training, were well equipped to venture into flamenco jazz or even mainstream flamenco if they were so inclined. Accordingly, several pianists took up flamenco in their manner, collectively establishing that instrument as an acceptable vehicle for flamenco, even if the guitar continues to reign supreme. The ranks of skilled pianists have even included some gitanos (Gypsies), notably Diego Amador, a self-taught pianist from a prominent family of flamenco musicians, and Pablo Rubén Maldonado and David Dorantes, both of whom studied the instrument in a more conventional manner.

A more general development was the modernization and globalization of music culture in Spain, which had diverse ramifications. One of these developments - in which Paco de Lucía again played a key role-was the advent of nuevo flamenco. While generally adhering to the established repertoire of songtypes (cantes/palos), nuevo flamenco featured through-composed songs, some-

as one texture along with arpeggio, rasgueo, tremolo, and thumb-driven alzapúa-, de Lucía's playing in these formats was essentially reduced to picado alone. 
times in an accessible, tuneful "pop" vein, with combo format and a somewhat expanded chordal repertoire played by guitarists. A related development from the 1980s has been the vogue - whether faddish or genuinely inspired — of fusions of flamenco music and dance with various other genres, such as North African/“Andalusian” art music, Indian kathak, and tap dance.

A parallel development was the belated interest in and availability of jazz in Spain. Particularly inspiring for young jazz musicians were the tours by Chick Corea of that country in the 1970s, during which the versatile pianist showcased his various Spanish-tinged songs, such as "Spain." Such an ambience could nurture the emergence of jazz players such as Pardo and Benavent who, while not conservatory-trained, could learn enough about jazz theory and practice from private lessons and other sources to develop their own talent.

The true flowering of flamenco jazz took place during the years around 1990. Aside from the emergence of a certain critical mass of interested performers and listeners, particular landmarks included the early and seminal albums of pianist Chano Domínguez (especially Chano and 10 de Paco in 1993-94) and the ongoing activities of Pardo and Benavent. These three musicians, indeed, have gone on to be central artists in the field of flamenco jazz; with their outstanding talent, originality, and productivity, they have done much to compensate for the decades of prior stagnation in the Spanish jazz scene. From the 1990s, the flamenco jazz field expanded into a lively and even fashionable scene, attracting the interest of many young Spanish jazz players as well as flamenco guitarists. Conservatories have produced an abundance of gifted pianists, horn players, and others who are solidly grounded in jazz and at least casually versed in flamenco.

Nowadays, flamenco jazz is performed in festivals in Spain, in jazz venues such as Madrid's Café Central and Calle 54, and on the broader Euro-jazz circuit, which offers more opportunities than does Spain itself. A few venues on the flamenco circuit might also stage flamenco jazz; Pedro Ojesto, a key figure in the movement, notes with pride that his group might play at Café Central one week and at flamenco club Casa Patas the next. Leading performers may put considerable effort into producing albums that, rather than being remunerative commercial ventures, serve primarily as documents and promotional calling cards and may be subsidized by grants from state or private institutions. Needless to say, a great quantity of flamenco jazz can be found on YouTube, much of itwhether live performances or entire albums--uploaded by artists themselves (such as Domínguez) on their own channels. ${ }^{6} \mathrm{~A}$ few artists have also produced peda-

\footnotetext{
${ }^{6}$ Such posts attest to the transnational nature of the genre's audience. A Chilean enthusiast, "Pianopablo," uploaded his transcription of Domínguez's "Oye como viene," eliciting grateful
} 
gogical booklets, such as Flamenco Jazz by Domínguez and Flamenco Jazz Translations by guitarist Marcos Teira (both with CDs) and especially the Flamenco Jazz Real Book, compiled by drummer and composer Guillermo McGill, which contains basic scores to sixty-four songs by himself, Pedro Ojesto, Alfonso Gamaza (d. 2009), Perico Sambeat, Jorge Pardo, and others.

As I shall discuss, many of the concerts and recordings advertised as "flamenco jazz" have lain, in terms of style and structure, firmly in the camp of one genre and have had little to do with the other. The variety of styles represented by diverse performers has also led a few observers to question whether flamenco jazz really exists as a distinct genre per se. However, the term has come to be widely used in titles of albums, pedagogical literature, and concert promotions, as well as by journalists and many musicians themselves. Moreover, while many performers have distinct approaches to the art, the 1990s saw the clear codification of a sort of mainstream approach, which is the primary focus of this article. However, before proceeding to this genre, a closer look should be taken at the aspects of traditional and modern flamenco in terms of their compatibilities with jazz and the avenues for expansion that they have provided to open-minded jazz players.

\section{FLAMENCO FORMS}

As the style and structure of flamenco have been described in so many publications, it will suffice at this point to merely give a concise sketch of some of its features and to discuss a few jazz adaptations of these in greater detail later in this article. Flamenco, as a genre that coalesced in the latter nineteenth century, comprises cante (singing), baile (dance), and toque (playing, especially of guitar); of these, it is toque - that is, the instrumental dimension of the art-that is most relevant to flamenco jazz. Traditional flamenco is primarily a vocal art, with the guitar serving to accompany the cante. However, solo guitar playing has long been recognized as a subsidiary idiom in its own right, and flamenco jazz is overwhelmingly an instrumental art form.

A given flamenco item invariably conforms to one of around a dozen common song-types, the generic term for which is cante (lit., singing) or palo, the latter term being more appropriate to instrumental renderings. Harmonically, some of these palos, such as alegrías, guajiras, and the verse sections of fandangos, are essentially in simple common-practice I-IV-V tonality. Chords in these contexts are overwhelmingly triads (or dominant $7^{\text {th }}$ chords), though a tonic A major chord can be enhanced with an added $6^{\text {th }}$ degree $(\mathrm{F} \#)$, and a D7 chord (as 
preceding a $\mathrm{G}$ chord in the verse section of a tarantas) could be voiced with an open-string $E$ (the $9^{\text {th }}$ ) on top.

More distinctive-sounding-and of more interest to flamenco jazz musicians - are those palos that use a modified form of Phrygian modal harmony, combining a Phrygian scalar basis with a major modal tonic chord. Thus, in the key of E Phrygian, these chordal resources would be:

\section{E F G Am (b) C Dm}

\section{II III iv (-) VI vii}

Note that the term "Phrygian" would properly denote a minor tonic chord (e.g., E minor), but in flamenco and Andalusian harmony, the tonic chord is in fact major; correspondingly, melodies in this modal harmonic system may employ either raised or lowered third scalar degrees, depending on context. ${ }^{7}$ The use of the raised third degree reflects the extent to which this tonal system is in part a modal harmony derived from the configuration, common in Arab music, corresponding to the Hijaz maqām or mode, roughly (in E): E F G\# A B C D. The quintessential chord progression, analogous to a $\mathrm{IV}-\mathrm{V}-\mathrm{I}$ or ii-V-I in mainstream jazz, is iv-III-II-I (la sol fa mi, or, in E: Am-G-F-E); indeed, it could be said that both jazz and flamenco share the use of a fundamental cadential progression. The role of the dominant - that is, the chord that demands resolution to the tonic-is played by the II (or "bII") chord, with vii as a substitute. The V7 (e.g., B7, in E Phrygian) chord is essentially absent in this tonality, though it might be used as a coloristic passing chord. ${ }^{8}$ The descending character of the 4-3-2-1 cadence could be said to provide the sort of directionality that is otherwise provided by 4ths movement in common practice and jazz harmony. However, the Andalusian cadence itself can be elaborated via a ("cycle 4") root motion progression by fourths, e.g., iv-vii (or VII7)-III-VI-bII-I, or Am-D7-G7-C7-F-E; in its prevalence and its typically cadential function, this progression could be seen as a counterpart to the iii-vi-ii-V-I "turnaround" in mainstream jazz. The modal tonic I chord is often enhanced with non-triadic tones, especially the $7^{\text {th }}$ and $b 9$ degrees, which do not, however, imply any

\footnotetext{
${ }^{7}$ There is no ideal term for this tonality. It is sometimes referred to as "flamenco" tonality, but such a designation obscures the fact that it is common in other Andalusian musics besides flamenco (including fandangos), and, in related forms, in much Turkish and Eastern European music (including klezmer) as I have discussed in detail elsewhere (Manuel 1989).

${ }^{8}$ A different usage is in the popular Paco de Lucía song "Sólo quiero caminar," where the B7 chord signals a modulation from E Phrygian to E minor (e.g., at ca. 1:16).
} 
instability or demand for "resolution" to the iv chord. In this article, this Phrygian tonic chord is notated as " $\mathrm{I}(7 b 9)$ " or $\mathrm{I}^{7 b 9}$." Different palos, as played on guitar (often with a capo), exploit the various sonorities obtained by open strings on that instrument. Thus, soleares (soleá) is most typically played in E Phrygian (in the fingering guitarists call "por arriba," or "on top"), bulerías in A Phrygian ("por medio," or "in the middle"), tarantas in F\# Phrygian, and granaínas in B Phrygian (or transpositions of these fingerings if a capo is used). Some typical $\mathrm{I}^{7^{\text {bq }}}$ voicings are shown in Figure 1. (Audio renditions of most figures in this article, with notations, are posted on YouTube and Vimeo. ${ }^{10}$ )

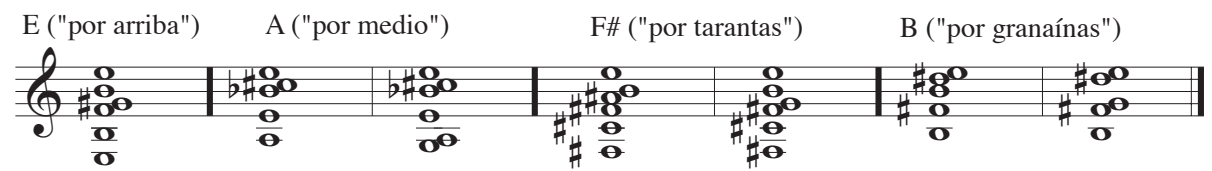

Figure 1. Typical Phrygian tonic voicings.

Some of the cantes/palos, such as tarantas, granainas, and fandango libre, are in free rhythm. ${ }^{11}$ Others, including those preferred in flamenco jazz, are metered, or rather, in compás. The latter term, however, denotes a more specific entity than a meter, designating instead a metrical entity with conventional accent points and chordal structures. The duple-metered compases of tangos and rumbas are fairly straightforward, but the 12-beat patterns of alegrías, soleares, bulerías, and siguiriyas are more complex. Some of these, and their flamenco jazz

\footnotetext{
${ }^{9}$ Spanish musicians have notated this chord in various ways, including (in the case of an E7b9 chord) "Emajb9," "Efrigio," "E frig" (E-Phrygian), and "E7b9flam." In flamenco jazz, as we shall note, the composer may desire some deliberate ambiguity as to whether the chord is to be heard as a Phrygian tonic or, for example, as a secondary or tertiary dominant seeking to resolve to a minor chord a fourth higher (e.g., preceding a ii chord in a passage in common-practice tonality). Hence, the preference in this article for the designation "E(7b9)," which specifies type but not function.

${ }^{10}$ At: https://youtu.be/M_Za-dXqnH0 and https://vimeo.com/197711760. (These may also be accessed by entering my name, and channel.) I thank guitarist Andres Jimenez and pianist Beth Robin for providing recordings of Figures 8 and 13, and 14 and 16, respectively.

${ }^{11}$ The cantes of tarantas, granaínas, and fandango libre are members of what is regarded as the Andalusian fandango family, alternating sung verses in the common-practice key of the relative major (a major third below the Phrygian tonic) with guitar interludes (pre-composed falsetas) in the Phrygian tonic. In solos, guitarists treat tarantas and granaínas essentially as fantasias in which they explore the sonorities available in those tonalities, with their characteristic use of open strings.
} 
adaptations, will be discussed further below, but introductory remarks about a few of them can be presented here. The compases of these palos bear a certain structural affinity (and historical link) to the 6/8-3/4 "I like to be in Ame-ri-ca" hemiola pattern so abundant in Latin American music. Soleares and alegrías could be regarded to some extent as medium-tempo variants of this form in the pattern $3+3+2+2+2$, but with special accents on beats $3,6,8$, and 10 (instead of 1 , 4, 7, 9, and 11). These accents are typically reinforced by the harmonic rhythm, particularly the move to the dominant (bII in soleares, V7 in alegrías) on beat 3 , and back to the tonic on beat 10 . The soleares basic pattern could be schematically represented as shown here, with a handy mnemonic for those who find such things useful: ${ }^{12}$

$$
\begin{array}{cccccccccccccccc}
1 & 2 & 3 & / & 4 & 5 & 6 & / & 7 & 8 & / & 9 & 10 & / & 11 & 12 \\
\mathrm{E} & - & \mathrm{F} & / & - & - & - & / & (\mathrm{F}) & (\mathrm{E}) & / & (\mathrm{F}) & \mathrm{E} & / & - & - \\
\text { TON-ic THEN up } & \text { to TWO THEN BACK TO } & \text { ONE (pause pause) }
\end{array}
$$

Bulerías - particularly popular in flamenco jazz-in some respects resembles (and to some extent evolved as) an accelerated version of soleares, with a distinction that beat one loses its accentual importance (provoking much discussion among analytically-minded flamencólogos or "flamencologists"). Guitar phrases may begin either on that beat or, more commonly, on beat 12, providing a superficial similarity to the "I like to be in Ame-ri-ca" hemiola. However, bulerías is better heard as a metrical entity that lacks a strong sense of downbeat but is instead based, in its conventional recurring ostinato, around the oscillation between the dominant bII at beat 3 , and the return to the tonic at beat 10 . Hence, in the mnemonic below, the vagueness I have tried to suggest in the "well we" anacrusis "filler" phrase: ${ }^{13}$

\footnotetext{
${ }^{12}$ For detailed analysis of soleares, see Manuel 2006. In that article, I also suggested another mnemonic: "I want TO live on A chicken FARM in SPAIN (pause pause)."

${ }^{13}$ While this beat count is standard among most musicians and teachers, some Spanish scholars and musicians have notated the compás in different ways in order to place the accented beats at the beginning of bars (see especially Jiménez 2015:149 and Chano Domínguez's notation of "Soleá blues" in his 2005 score booklet.) There is no ideal way to notate an entity like bulerías, especially since it is typically rendered in an irregular manner (and does not consistently stress beat 12 , not to mention beat 1 ). I prefer the more standard notation, which does, however, oblige the reader to accept that this is a 12 -beat metrical entity which does not have a strong initial downbeat and which often stresses internal beats rather than initial ones.
} 


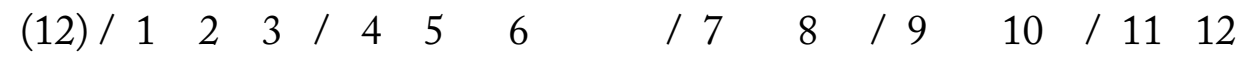
(A) / - - Bb / - - (Bb or C) / - (Bb) / - A / - (well) we go UP then we WORK our WAY back DOWN and well

In both these patterns, beat 10 is frequently the site of a staccato cadential strum, called a remate ("finishing off") or "cierre" (closing), which is also present, at different points, in the other palos. A guitarist might play the compás of bulerías more or less as shown in Figure 2.

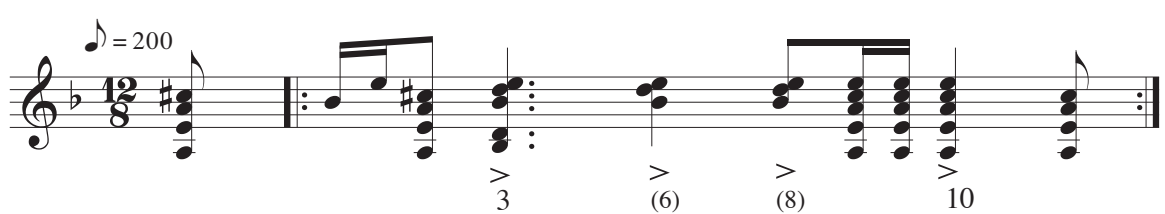

Figure 2. A typical guitar rendering of the bulerías compás.

In performance, accentuation in bulerías is highly variable. Extended passages may subdivide the compás into regular twos, or into threes rather than the hemiola pattern; harmonies may meander, or even sit on the tonic for several compases. However, at various points the compás would in fact stress the 3 and 10 axis, most typically as shown above. It is this sort of harmonic rhythm that would most characteristically distinguish a genuine bulerías from a flamenco-jazz item which, despite being labeled "bulerías," is essentially a free-form romp in $6 / 8 . .^{14}$

Traditional bulerías and soleares share a conventional verse structure, which could be crudely schematized as follows: after an introductory guitar falseta (a pre-composed passage), a line of verse is sung, with the guitar playing versions of the patterns shown in Figures 1 or 2, oscillating between Phrygian tonic and bII dominant; this line is repeated; then, a second text line is sung, and the guitar switches (in the cambio or "change") to VI at beat 10, and thence back to bII at beat 3 and the tonic at 10; this line may be repeated. A conventional soleares or bulerías might consist of a series of four or five such verse sections punctuated by guitar falsetas. In modern times, and especially in nuevo flamenco, a bulerías verse section is likely to take the form of a pre-composed entity with an original melody set to a specific harmonic progression.

Two other metered palos/cantes common in flamenco and especially flamenco jazz are tangos and rumba. Both can be notated in 4/4. The basic two-

\footnotetext{
${ }^{14}$ In flamenco parlance, it is common to refer to an item as being "por bulerías" (or por soleá etc.)-i.e., "in bulerías compás" - rather than being "a bulerías" per se. Hence, e.g., "Voy a cantar por bulerías"- "I'm going to sing in bulerías."
} 
bar compás of tangos could be schematized as in Figure 3, with its characteristic oscillation between bII and I, and its cadential cierre on beat 3 of the second bar. The palmas, or hand-clapping, is a distinctive element of the rhythmic accompaniment and should ideally be present, as in bulerías as well. The conventional tango verse section presents a line sung to this pattern, moves to iv, and thence downward by fourths back to the tonic. Sometimes inserted is a turnaround-type refrain pattern like that shown in Figure 6 later in this article.

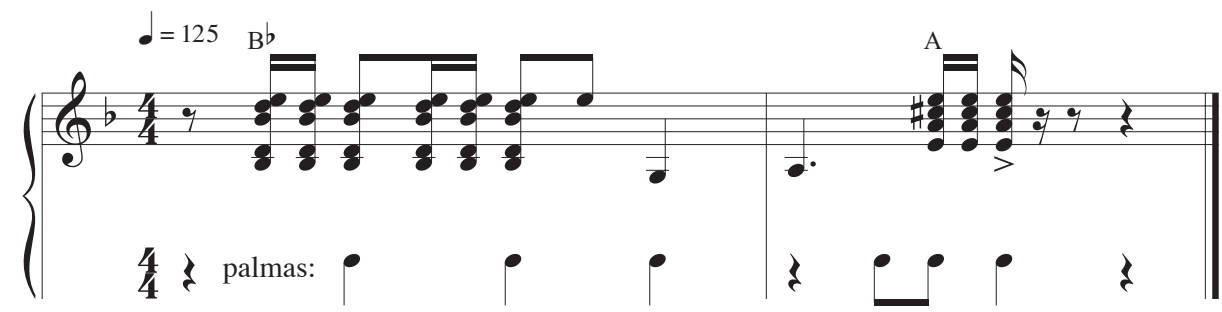

Figure 3. Tangos compás.

Rumba, in flamenco, denotes a less specific entity, distinguished primarily by its 3-3-2 rhythmic syncopation (which could be said, like the word, to derive from Cuban popular song of the first half of the $20^{\text {th }}$ century). In nuevo flamenco and flamenco jazz, the designations "tango" and "rumba" are used quite loosely to denote any song or item suggesting those rhythms.

If tango and rumba are relatively light genres (in the cante chico category), siguiriyas is an important constituent of the cante jondo- "deep song"-category. It has a somewhat archaic modal flavor, with chordal accompaniment essentially oscillating between tonic and dominant bII, in a sort of displaced hemiola pattern: one-two-one-two-one-two-three-one-two-three-one-two. Siguiriyas occasionally appears in flamenco jazz contexts, though it is not nearly as common as bulerías and tangos.

Finally, flamenco, both in its vocal and instrumental dimensions, also constitutes a style; in guitar playing, this would comprise the distinctive uses of arpeggio, rasgueo (strumming), picado (single-note runs), repetitive thumbpicked patterns called alzapúa, and guitar-style tremolo (in which thumb-picked bass arpeggio notes are each followed by four strokes on a melody note). In a word, as an instrumental genre, flamenco could be said to comprise a tonal/harmonic system, a set of palos or song-types, and a distinctive style of playing. As we shall note, flamenco jazz productions have engaged with these discrete dimensions in different ways, and often individually rather than as a complete package. 
FLAMENCO AND JAZZ: COMPATIBILITIES AND INCOMPATIBILITIES

The creators and performers of flamenco jazz, in its diverse forms, have had to confront the challenge of negotiating and overcoming the considerable stylistic, structural, and aesthetic differences that exist between the two constituent genres. At the same time, the genre would not be able to exist, much less flourish, were it not for the sorts of inherent compatibilities between the two idioms. One kind of oft-noted affinity is that both flamenco and jazz have sociohistorical roots in the subcultures of marginalized subaltern minorities, that is, Andalusian Gypsies and Afro-Americans, respectively. Several flamenco musicians have spoken of this similarity, which undoubtedly has some genuine affective resonance for them. ${ }^{15}$ However, this article focuses on the more mundane level of purely formal attributes which have provided the bases for the fusions of the two genres.

One fundamental similarity, often mentioned by performers, is the role of improvisation in both genres. Improvisation is, of course, fundamental to jazz, whether in the form of interactive rhythm-section accompaniments or, more prominently, solos consisting primarily of single-note melodies improvised over the chord changes of the song. In flamenco, improvisation is of a somewhat different nature and is considerably less extensive. In the traditional format of cante with guitar accompaniment, the vocalist may spontaneously choose which verses to sing, in the strophic sequence that constitutes an item (the term "song" is not appropriate), but these verse renderings, in spite of admitting some degree of interpretive nuance, are generally sung to established models (estilos, lit. "styles"). For his part, the guitarist must adapt his accompaniment to the vocalist, which he does in a flexible manner which gives the entire item a loose, improvisatory, spontaneous feel. In between the vocal verses he plays falseta interludes, which he chooses freely from his learned repertoire. However, as mentioned above, the falsetas themselves are pre-composed, and are often accordingly intricate gems with varied textures rather than mere tunes. There is no tradition of improvising single-note melodies as in jazz. For their part, solo guitar items are even less spontaneous; traditionally, or informally, these would typically consist of strings of falsetas. Nowadays, even the order of these falsetas may be pre-determined, such that the solos acquire the character of through-composed entities (and are accordingly given evocative titles).

\footnotetext{
${ }^{15}$ Flamenco guitarist Tomatito noted how both genres "emerged as a response to discrimination, a cry of suffering, or the joy of liberation" (in Cleveland 2014:48). Similarly, Jorge Pardo stated, "Flamenco is like the blues, they are two ancestral musics which come from one's gut, and have evolved in a parallel manner" (in García Saleh 2009; all translations from Spanish in this article are by the author).
} 
A certain parallel to jazz rhythm-section improvisation can be found in the ensemble accompaniments in many nuevo flamenco songs. Nuevo flamenco is the umbrella term for the various innovative forms of the genre that have emerged since the 1970s, largely as inspired by Paco de Lucía and his collaborators. As mentioned, however, the single most characteristic form of nuevo flamenco consists of pre-composed vocal songs (i.e., with fixed vocal and chordal patterns, rather than the standard compás patterns of traditional cantes). Whether live or in the recording studio, these songs are typically accompanied by a combo consisting of one or two guitars, bass, cajón (a wooden box, with a snare, struck with the hands ${ }^{16}$ ), and perhaps a flute or some other instrument. While commercial recordings may tend to be highly produced, slick entities, on various occasions the accompaniment played by the flamenco "rhythm section" may admit some spontaneity, and it is not surprising that some of the most popular accompanists - such as Benavent - come from jazz backgrounds. On some occasions, an instrumentalist may be allowed a few phrases of solo improvisation, but these are limited in scope. Flautist Jorge Pardo observes:

In flamenco you have to say something interesting in a very short time... It's very direct and rapturous, and everything has to have vigor and fire, without lowering the level. In jazz the improvisation is more relaxed, you can take time to get settled in the chord changes and build up to a crescendo, to a climax if it happens, and even if not, it can still be a nicely played phrase. These [flamenco and jazz] are two things that are quite difficult to marry, but it's what attracts me. ${ }^{17}$

On perhaps the most immediate level, it is the parameters of rhythm and harmony that are the key sites for creative syncretism. In terms of rhythm, most flamenco jazz tends to conform, whether loosely or closely, to the compás of either tango, rumba, or bulerías, whose forms have been schematized above. These terms are used rather unsystematically in flamenco jazz; as mentioned, the term "tango" might be used on an album label to describe almost any song in 4/4, and "bulerías" any item in 6/8, although in other cases the performers would make a clear effort to maintain the actual structural feel of these entities, with their characteristic harmonic rhythms, cadential cierre points, and other features. The quadratic rumbas and tangos are generally in "straight-four" feel-i.e., with duple subdivision of beats - rather than the swing rhythm typical of jazz, and the $12 / 8$ bulerías is typically too fast (e.g., $M M=$ ca. 250) to accommodate triplet

\footnotetext{
${ }^{16}$ Like so many other innovations, the cajón was introduced by de Lucía, who adopted it after hearing it in Afro-Peruvian music.

${ }^{17}$ In Fernández 2013:10-11.
} 
subdivision. Nevertheless, as we shall see, many flamenco jazz musicians have found adaptation of the bulerías structure to be one of the most fruitful, challenging, and exciting aspects of the genre.

Another point of latent compatibility between jazz and flamenco involves the sort of chromaticism that exists in each. Chromaticism is of course basic to jazz, and it also has its own presence--however distinct in form and generative logicin flamenco. This is most evident in the use of both raised and lowered forms of the third scalar degree. Thus, for example, in the key of A Phrygian, the the F and $\mathrm{C}$ chords call for a $\mathrm{C}$ natural, while the $\mathrm{A}$ major tonic chord features $\mathrm{C} \#$. In melodies - whether played on the guitar or sung-, the use of the $\mathrm{C}$ or $\mathrm{C} \#$ would be largely determined by context and convention. In modern flamenco, it would not be unusual to hear them used adjacently in descent (e.g., $\mathrm{C} \#-\mathrm{C}-\mathrm{B} b-\mathrm{A})$. One might note, here an apparent similarity with the blues-derived use of both third degrees in jazz, and the affinity is not completely insignificant, but on the whole the ways these notes are juxtaposed are entirely different in the two genres. Other non-Phrygian scalar tones can also be introduced in various contexts; the natural second degree might appear in a $\mathrm{C}-\mathrm{B}-\mathrm{B} b-\mathrm{A}$ descent, and the flatted fifth would occur (including in vocal melodies) in a predominant VI7 chord segueing to a bII cadence (e.g., F7-Bb-A). For its part, the leading tone (e.g., $\mathrm{G \sharp )}$ can appear as a neighbor tone to the tonic or as a passing chordal tone as in Figure $5 \mathrm{c}$ below. Collectively, these sorts of chromaticism familiar in flamenco provide affinities with jazz, which musicians can creatively exploit and elaborate.

While I have introduced flamenco harmony above, at this point it may be useful to note some of its particular sorts of compatibilities with, and differences from, jazz harmony. As I have mentioned, the traditional flamenco chord vocabulary includes sonorities, from the $\mathrm{I}^{\prime 6}$ chord to the Phrygian tonic $\mathrm{I}^{7 b 9}$ chord, which, like jazz voicings, include non-triadic tones. By the early 1970s, Paco de Lucía had established the minor 9 chord as a familiar sonority, as shown in Figure 4, where, in the tarantas key of $\mathrm{F} \#$ Phrygian, it first precedes the tonic and then the subdominant $(\mathrm{Bm})$.

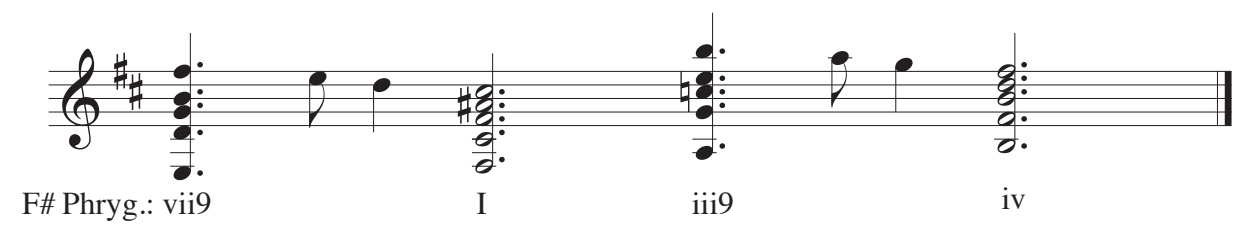

Figure 4. Minor 9 chords in tarantas. 
Particularly common even in traditional playing are chords whose non-triadic tones consist of open strings on the guitar. ${ }^{18}$ Figure 5 shows various voicings or variants of the dominant bII chord in A Phrygian. Of these, the first three voicings of $\mathrm{B} b$ chords (Figure $5 \mathrm{a}$ ) are entirely traditional, with the non-triadic $\mathrm{G}$ and $\mathrm{E}$ tones being open strings on the guitar. The fourth voicing (5b), although quite familiar nowadays, is a distinctively modern-sounding $\mathrm{B} b$ sonority, which could be seen as a $\mathrm{B} b^{9+11}$. Figure $5 \mathrm{c}$ shows another common pattern, in which the A Phrygian tonic chord is approached from below, that is, via the minor vii chord, with a passing chord substituting a $G \#$ leading tone for $G$ in the bass. Most such chords, though effectively serving as dominant substitutes resolving to the tonic $\mathrm{A}^{7 \mathrm{tg}}$, do not lend themselves to any sort of common-practice or even jazz-informed analysis. They can be said to have a different generative logic than is operant in mainstream jazz, where, for example, a dominant 13 chord (e.g., GF-A-B-E) can be understood as incorporating extensions of thirds, viz., conceptually adding to the triad the $7^{\text {th }}, 9^{\text {th }}, 11^{\text {th }}$ (typically omitted) and $13^{\text {th }}$ degrees. Thus, in the $\mathrm{B} b$ chords shown in Figure $5 \mathrm{a}$, the $\mathrm{E}$ functions not as a " $b 5$ " but as a sort of an appoggiatura, or drone--an atavism from flamenco's roots in purely modal music. Nevertheless, the familiarity of such chords in flamenco can reflect a certain inherent aesthetic openness to altered chords with non-triadic tones, which can be exploited in its way by jazz musicians. For its part, the $\mathrm{B} b^{9+11}$ chord of Figure 5b, although well accepted in mainstream flamenco nowadays, has an unmistakable jazzy flavor to it, and has been highlighted accordingly in various flamenco jazz productions. The pattern in Figure $5 \mathrm{c}$ is also pervasive in modern flamenco and illustrative of chromaticism in that genre. While the first chord is a straightforward Gmin7 (vii, a dominant substitution in A Phrygian), the second chord is less amenable to standard analysis; it is best regarded as another Gmin7 chord but with a passing $A b$ in the bass and an appoggiatura-like $E$ (the $6^{\text {th }}$ degree of the $\mathrm{G}$ chord, and the $5^{\text {th }}$ of the subsequent A chord) on top. Figure $5 \mathrm{~d}$ shows another modern flamenco sonority, in which a minor $9^{\text {th }}$ chord on the flat second degree (here, a $\mathrm{B} b$ minor chord) substitutes for the standard $b \mathrm{II}$ chord. The $\mathrm{B} b^{\mathrm{m} 9}$ chord fits very easily with the tonality, since its $\mathrm{D} b(=\mathrm{C} \#)$ and $\mathrm{C}$ natural are both present in the Phrygian flamenco scale. In flamenco jazz, the $\mathrm{B}^{\mathrm{m} 9}$ can easily segue up a fourth to an $\mathrm{E} b^{9}$ chord, which can itself resolve downward to the A. ${ }^{19}$ Finally, appended here as $5 \mathrm{e}$ is a typical riff which, though

\footnotetext{
${ }^{18}$ See Manuel 1986.

${ }^{19}$ A prominent instance of the minor bII chord (in the key of E Phrygian) occurs near the opening of de Lucía's popular nuevo flamenco song "Sólo quiero caminar" (on the eponymous album). Chano Domínguez, in his flamenco jazz version of this song (at .28 on 10 de Paco), adds the subsequent chords shown in Figure 5d.
} 
clearly in the tonality of A Phrygian, illustrates flamenco melodic chromaticism by including every note in the octave.

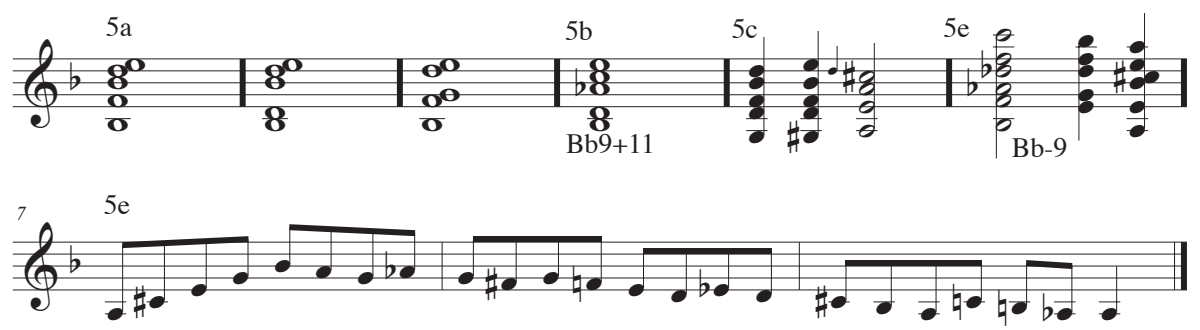

Figure 5. Conventional voicings of dominant or non-tonic chords (in A Phrygian); 5e: chromatic riff.

Other points of contact and compatibility between standard flamenco harmonies and jazz can be found in the aforementioned progression by 4ths/5ths from minor iv to the Phrygian tonic. As noted above, the iv-III-II-I Andalusian cadence is often filled in, as it were, with chords moving by fourths (e.g., in A Phrygian: Dm-G7-C-F7-Bb-A); this progression contains not only cycle 4 movements familiar to the jazz player, but also a passing ii-V-I-type cadence (on C). The jazz affinities latent in this progression can be exploited in other ways as well. Figure 6a (which does not attempt to portray actual guitar voicings) shows a common traditional refrain passage in tangos; both in its function as a coda to verses and in its cycle 4 movement, it closely resembles a standard jazz turnaround, with the primary difference being that it concludes on the Phrygian tonic rather than the common-practice major tonic. Figure 6b shows how, with a slight alteration in voicing, this pattern becomes a typical jazz progression with conventional G13 and F13 voicings; in Figure 6c, it is "jazzed up" in another manner, with chromatically descending passing chords $^{20}$ :

\footnotetext{
${ }^{20}$ Figure $6 \mathrm{c}$ is loosely adapted from the beginning of "Bohemio," by Pedro Ojesto's Flamenco Jazz Company, on Nikela.
} 

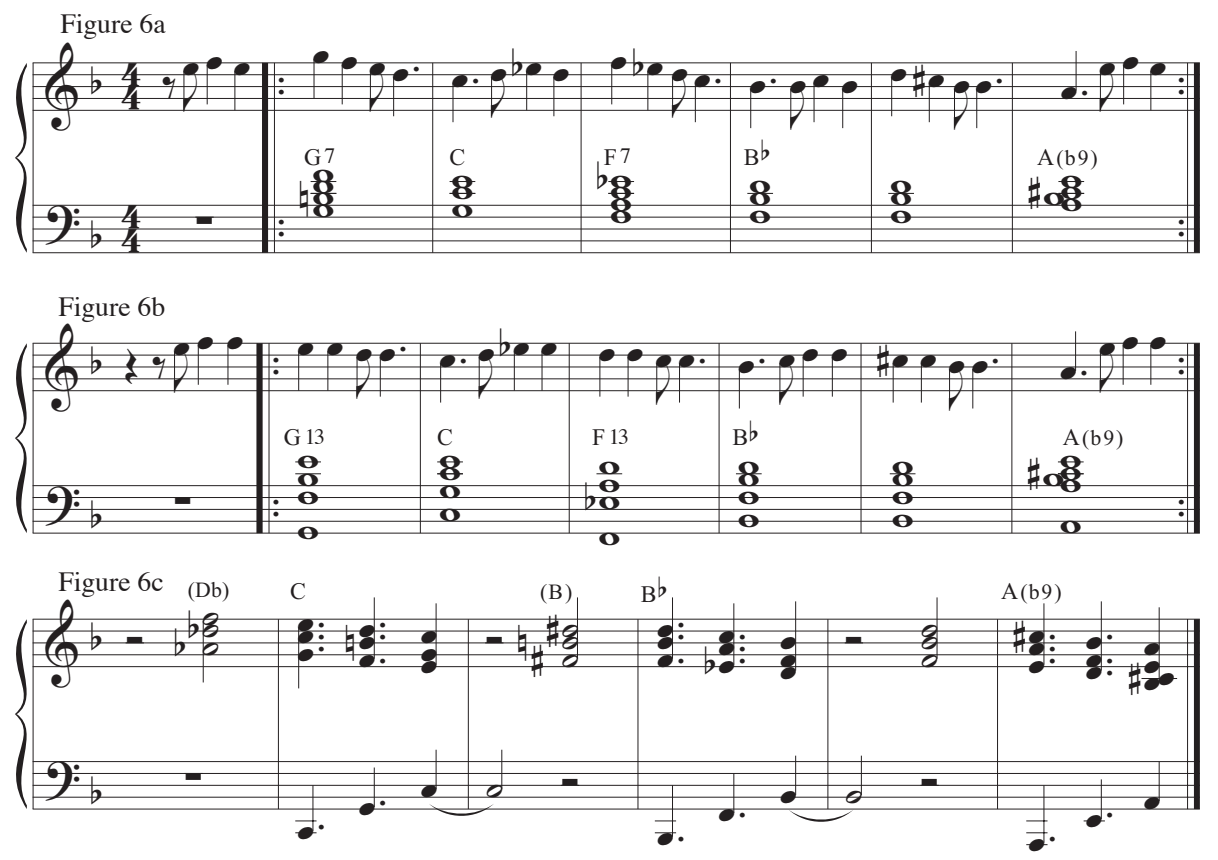

Figure 6. 6a: Typical "turnaround" in tangos. 6b: Turnaround with jazz voicings. 6c; turnaround with chromatic passing chords.

Meanwhile, since the 1970s, if not earlier, a minor ii-V-I progression can also occur in flamenco, in the palo of bulerías in $\mathrm{A}$ minor-i.e., $\mathrm{B}^{-5-7}-\mathrm{E} 7-\mathrm{Am}$ (or in the minor turnaround: Dm7-G7-C-F-B-5-7--E7-Am).

Since the 1970s, especially as inspired by de Lucía, flamenco harmony has been expanded and elaborated in certain ways, some of which provide further opportunities for elaboration by jazz players. Some of these new harmonic developments have become familiar and conventional, recurring in pop-tinged nuevo flamenco compositions and in guitar falsetas. Others may be regarded as adventurous, idiosyncratic innovations which have not come to be widely adopted by musicians other than their inventors. In the first category, one might note a by-now conventional nuevo flamenco sequence in which the Phrygian tonic is temporarily replaced by a minor chord, as in the chord progression in $\mathrm{A}$ Phrygian: Gm7-Am7-Gm-Gm/G $\#-A^{7 b 9}$, with the last three chords conforming to Figure $5 \mathrm{~d}$ above. ${ }^{21}$

${ }^{21}$ This progression has become something of a cliché in nuevo flamenco verse sections. It can be heard, among elsewhere, in Paco de Lucía's "Sólo quiero caminar," Remedios Amaya's "Me voy contigo" (both on the eponymous albums), and Miguel Poveda's "Pastueño" (on Suena Flamenco). 
Another modern technique involves modulating (or simply shifting) from one Phrygian tonic to another. This technique, as well as the minor tonic substitution, is illustrated in Figure 7, which shows how a popular light flamenco song of 1949 ("El emigrante") could be set to nuevo flamenco harmonies. The section could be said to commence with a I-bII-I phrase in A, except that the first tonic chord, as in the pattern mentioned in the previous paragraph, is rendered as a minor chord (i.e., Amin-Bb- $\mathrm{A}^{7 b 9}$ ). Then the same pattern is duplicated, with a different melody, at $\mathrm{C}^{7 b_{9}}{ }^{22}$ This practice can be seen as maintaining, with variation, the single most characteristic feature of flamenco harmony: the bII-I $\mathrm{I}^{\mathrm{b}^{9}}$ cadence. $^{23}$
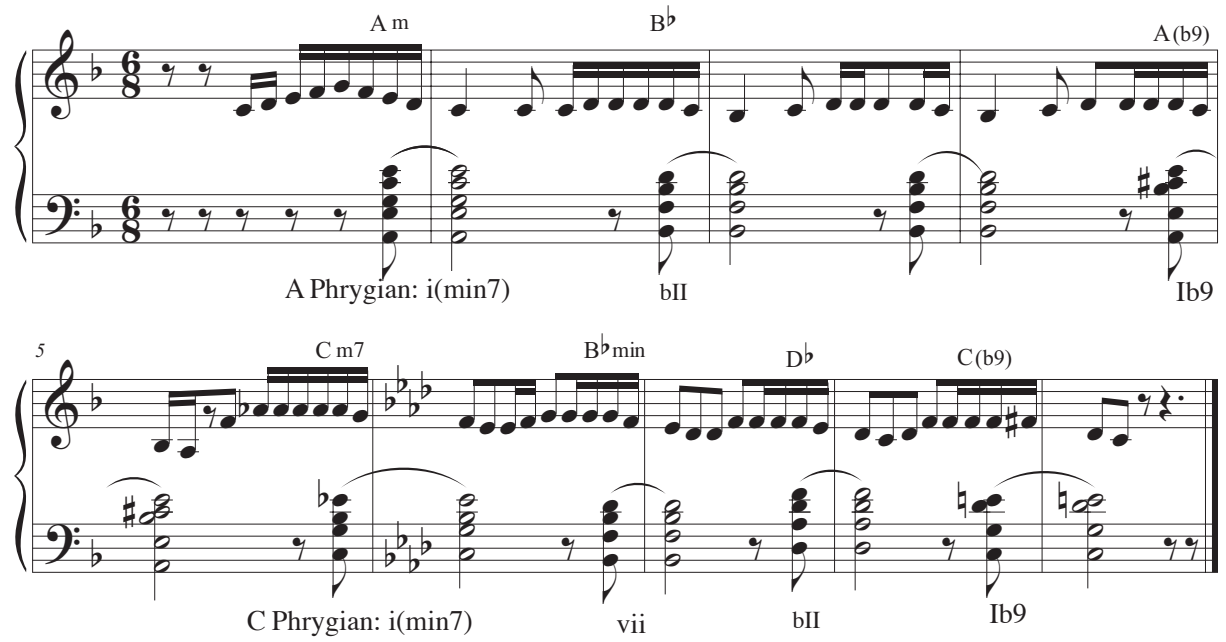

Figure 7. Nuevo flamenco excerpt illustrating tonic modulation.

${ }^{22}$ See Vicente Amigo and El Pele, "El emigrante," on Tributo flamenco a Don Juan Valderrama. It may be pointed out that this sort of modulation of Phrygian tonic can pose some technical difficulty for the flamenco guitarist, who, accustomed to playing basic tonic and bII chords in first position, in the new Phrygian key may need to devote his index finger to barring the tonic fret in order to generate familiar chords. Meanwhile, many flamenco vocalists, who sing by ear in the familiar modes, might also be challenged by such modulations. However, guitarist Vicente Amigo and vocalist El Pele would be easily able to negotiate them.

${ }^{23}$ This fundamental cadence can be recontextualized in other ways as well, as in guitarist Gerardo Nuñez's popular bulerías "Calima" (on Jazzpaña II). Several renditions of this piece can also be found on YouTube. Another section of it reiterates the rock-style "Gloria" progression (B b-F-C major), which is also unconventional in flamenco (as well as jazz). Most of this piece is in the key of $\mathrm{C}$ major, but after repeating plagal IV-I (or F-C) oscillations, flamenco harmonies are introduced in the form of the chord sequence: $\mathrm{G} b-\mathrm{F}(7 b 9)-\mathrm{D} b-\mathrm{Cmaj}$. The $\mathrm{G} b-\mathrm{F}(7 b 9)$ can be heard as a bII-I(7b9) cadence in F Phrygian, followed by the VI chord ( $\mathrm{D} b)$ in that tonality, which serves as a pivot chord, doubling as bII resolving (back) to the tonality of $\mathrm{C}$-but $\mathrm{C}$ major, not $\mathrm{C}$ Phrygian. 
Some typical modern flamenco harmonies are shown in Figure 8, which could represent a schematic reduction of the guitar introduction to a nuevo flamenco song in A Phrygian. ${ }^{24}$ Visible here are: the substitution of a $\mathrm{D}^{7 b_{9}}$ for a $\mathrm{Dm}$ (i.e., a $\mathrm{IV}^{7 \mathrm{~b} 9}$ chord in place of a minor iv chord), the somewhat unclassifiable descending chords in mm. 5-6 preceding the bII dominant, and the substitute dominant chord in bar 9. While this sonority could be labeled as a $\mathrm{Db}^{\prime} 6$ chord, it is more coloristic than teleologically functional. The similar $\mathrm{D}^{\circ 7}$ chord in bar 12 also works well in the Phrygian flamenco context, with its combination of both $\mathrm{C}$ and $\mathrm{D} b(=\mathrm{C} \#)$; this chord can also be "planed" upwards as shown in the same bar.

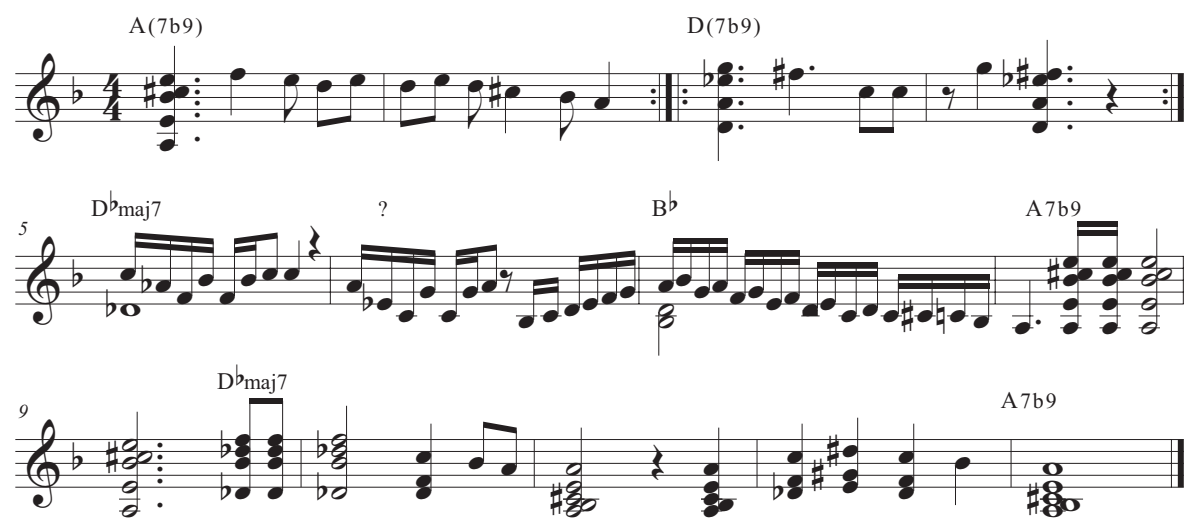

Figure 8. Nuevo flamenco excerpt.

At this point, we may summarize that conventional and modern flamenco harmony comprises some phenomena and practices shared with jazz harmony, viz., dominant and pre-dominant function chords, chord substitutions, planing effects, modulations, altered chords with non-triadic tones, cycle-5 turnaroundtype sequences, and standard cadential progressions (in flamenco, the Andalusian cadence in its various forms). Most of these features constitute elements of a system of modal harmony whose generative logic-rooted, for example, in Phrygian and Hijaz-type modes-is entirely different from that of commonpractice harmony and jazz. However, their very presence, as general entities, constitutes a point of compatibility that musicians can exploit; with a relatively

${ }^{24}$ This notation is very loosely based on "Pastueño," by Miguel Poveda, on Suena Flamenco. The accompanying audio example is played by Andres Jimenez. 
limited amount of "tweaking," jazz musicians can use these features to build a coherent hybrid harmonic language.

In surveying flamenco harmony, mention should be made of the various sorts of idiosyncratic innovations that have been devised by modern guitarists but have not necessarily entered wide circulation. Such new sonorities can be found in guitar falsetas, or in nuevo flamenco songs, where they might be conceived of as chord changes over which the guitarist or others could solo, as in jazz. Such chord progressions are characteristically created by guitarists who wish to expand and modernize flamenco tonality, but who do not have background in jazz (or classical music). Some of these sorts of progressions might sound eccentric and awkward to some listeners, as they may lack such things as movement by fourths or any sense of evident directionality. However, some musicians and listeners certainly enjoy them. Songs such as de Lucía's "Chiquito" contain several such passages, akin to that schematized in Figure 9.

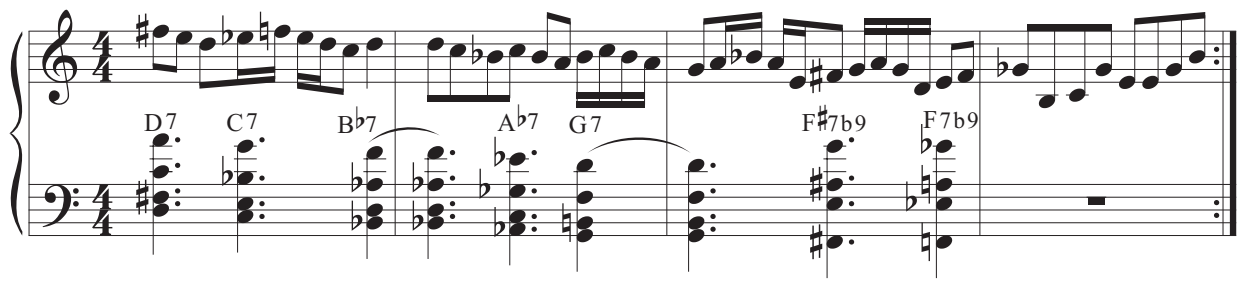

Figure 9. Modern flamenco progression with non-directional chords.

Several of de Lucía's songs (especially rumbas and tangos, rather than the more harmonically prescribed bulerías and soleares) illustrate his attempts, like those of others, to create a new, modern flamenco harmony, that, in accordance with his background, shares nothing in particular with jazz, rock, or pop models. As suggested, some such songs may be composed partly as suitable vehicles for "head-solos-head" improvisations, whether in an idiosyncratic flamenco style by guitarists such as de Lucía or by eclectic jazz players such as Pardo. In this latter category are de Lucía songs such as "Playa del Carmen," "Chiquito," "Convite," and especially "Ziryab," which is often played by flamenco jazz combos. "Ziryab" features some of the elements noted here, including altered chords (especially in tarantas configuration), leaps from one Phrygian tonic to another, shifts from Phrygian to major tonalities, and assorted progressions that do not conform to any familiar form of harmonic logic or directionality. Jazz players like Pardo, Domínguez, and Chick Corea find ways of setting jazz-type lines to these chords, while flamenco guitarists such as de Lucía, Sergio Monroy, and José María 
Bandera improvise over the changes in their own idiosyncratic modern-flamenco style, generally consisting of diatonic, single-note picado scales over the chords. ${ }^{25}$ This sort of modern flamenco harmony merits its own separate study.

From the early 1990s the quantity and diversity of assorted flamenco jazz productions expanded dramatically, especially as a new generation of formally trained, eclectic jazz players discovered that their nation's flamenco tradition offered a rich resource for cultivating a dynamic and original genre. As mentioned, these diverse productions have varied considerably in approach. Many could be situated on a stylistic continuum with flamenco at one end and jazz at the other, and indeed, as mentioned, some are so exclusively in one camp or the other that their self-description as "flamenco jazz" may seem little more than a publicity gimmick. However, as we have noted, flamenco, like any genre, is a multi-dimensional entity, comprising conventions of rhythm, harmony, style, song structure, and other parameters, and flamenco jazz musicians have been able to engage selectively with these in diverse ways. For that matter, the notion of "jazz" itself is multi-dimensional and can comprise such elements as small combo format (with bass, drums, and perhaps sax), improvisation in head-solos-head format, and, last but not least, a conventional harmonic language and characteristic sorts of melodies. Flamenco jazz musicians, in their diverse endeavors, might naturally adopt and engage with one or more of these entities and not others. In this section, while not attempting a broad survey, I will mention a few of the approaches taken in productions on the antipodes of the stylistic gamut, and then look in some detail at what might be regarded as a mainstream flamenco jazz style.

In plotting diverse sorts of flamenco jazz on a spectrum, it should be noted that a great many productions involve juxtapositions of the two genres, rather than (or alongside) structural syntheses. ${ }^{26}$ In some cases, a jazz-based piece will feature, for essentially coloristic effect, a flamenco vocalist, who sings an "ayayay"

\footnotetext{
${ }^{25}$ Despite my attempts to be open-minded and open-eared, I must confess that I find many such improvisations to sound forced and ungainly, as if some flamenco guitarists are still in the process of trying to create a soloing style in a genre which has no such tradition, and they have yet to learn how to craft melodic lines that could coherently connect the disjointed chords of some modern flamenco.

${ }^{26}$ In this category might be placed the collaborations of jazz bassist Dave Holland with flamenco guitarist Pepe Habichuela and his son Josemi Carmona (José Miguel Carmona, a leader of the eclectic group Ketama). The most characteristic of these items could be described as essentially nuevo flamenco songs by Carmona, with some passages foregrounding the conventional flamenco playing of Habichuela, and, alternately, solos played by Holland in his idiosyncratic style. Holland himself has expressed his indifference to the term "flamenco jazz" in relation to this music (in interview accessible at: https://www.youtube.com/watch/?v=OOjCU6ZqxyI). Meanwhile, the more definitive flamenco bass style has been that of Carles Benavent.
} 
warm-up phrase (the temple) and a line or two of verse. Or similarly, the jazz players may lay out for an interlude in which a flamenco guitarist is featured. Not infrequently, an ensemble production might include two guitarists: a jazz player, on electric guitar, and a flamenco guitarist, who would each be foregrounded in different sections of a song; often, it may seem that the arranger has made a deliberate effort to work the flamenco singer or guitarist into the fabric of the piece at some point, even if this person is not able to contribute to the jazzier sections. Accordingly, if most flamenco guitarists are not conversant with jazz, most flamenco vocalists are typically even more "limited" in this sense, in that despite what may be their prodigious talents, they do not read music, are unfamiliar with jazz harmonies, and are generally hard-pressed to extend their melodies beyond the conventional diatonic modes and phrase patterns (although an outstanding exception is Antonio Lizana, discussed below.)

Many innovative productions that are labeled "flamenco jazz"-whether by performers, promoters, or journalists—can be seen to bear little formal relation to jazz, even if they may take place at events like the Montreaux Jazz Festival. As discussed above, Paco de Lucía's collaborations with guitarists like John McLaughlin, and the music of his sextet, bore certain oft-noted affinities with jazz in the emphasis on soloing, in single-note riff style, and in head-solos-head format; however, in terms of harmonic language and melodic style, his music was not jazz unless that word is used in such an inclusive manner as to be almost meaningless. Similarly, it is conventional in histories of modern flamenco to cite the 1968 recordings in which jazz sax player Pedro Iturralde invited de Lucía to accompany him. However, in most of these items, such as the soleares, Iturralde simply plays standard flamenco vocal lines, such that the product is really instrumental flamenco rather than any kind of jazz. Thus, the use of an instrument such as tenor sax does not in itself imply any engagement with jazz.

The same could be said of piano, or even piano-bass-drums format. As mentioned, in recent decades the piano has come to be accepted and legitimized in some circles as a suitable instrument for flamenco. With the addition of bass and percussion (whether cajón or trap set) having become familiar in nuevo flamenco since the 1970s, piano trio format-often with florid piano improvisations-has also become familiar in the flamenco world. However, this format need not imply fusion with jazz, even if it is sometimes described thusly. Emblematic in this regard is the music of David Peña Dorantes (b. 1969), a classically trained pianist from a gitano flamenco family, who often performs in trio format with extended improvisations over pre-composed flamenco harmonies. His music is sometimes characterized by others as flamenco jazz, but the jazz elements in his playing are in fact minimal, and he himself appears to prefer to describe his music as, for example, the "Free Flamenco Trio" rather than as flamenco jazz. 
On the other end of the stylistic continuum are the considerable number and variety of flamenco jazz undertakings that are more redolent of jazz than flamenco. Some entities routinely cited by "flamencologists" can be readily dispensed with in this sense. Miles Davis's song "Flamenco Sketches" has nothing to do with flamenco. Even the "Soleá" in his Sketches of Spain, although a languid rumination in Phrygian mode, has no distinctive flamenco features and is certainly not a soleá/soleares. Or one might mention in this regard such productions as Niño Josele's album ( $\mathrm{Paz}, 2006)$ of Bill Evans songs; Josele is primarily a flamenco guitarist, but his settings of tunes such as "Waltz for Debby" are overwhelmingly in a soft jazz style with only ephemeral insertions of flamenco passages.

Before continuing in this vein, however, it should be emphasized that the presence or absence of flamenco features in relevant sorts of music has nothing to do with their aesthetic merit. Representative in this sense are various productions by Chick Corea, such as the album My Spanish Heart. In this recording Corea, without incorporating flamenco per se, has clearly taken what he liked from Spanish music (from bullring-style trumpets to Phrygian tonality), while also indulging in some playful exoticism, as in the cover showing him garbed as a toreador. In the song "La fiesta" (on Return to Forever, 1972), he and Joe Farrell (sax) take brilliant solos over a Phrygian E-F-G-F-E vamp in fast 6/8. The song is not a bulerías, nor is it labeled thusly, and there would of course be no point in criticizing it for not being so. In fact, Corea-especially in songs like this-has been a primary inspirational figure for flamenco jazz players. ${ }^{27}$

At the same time, the degree of a jazz player's familiarity with flamenco may naturally affect the depth of his or her engagement with it, as may be noticed by enthusiasts. This point was stressed to me by pianist, composer, and pedagogue Pedro Ojesto, a central figure in the flamenco jazz movement. Ojesto stated that his goal is "to play a jazz that is deep in flamenco" in a way that might not be possible for the jazzman who lacks an intimate knowledge of flamenco. He explained to me:

A jazz player might do a standard like "Round Midnight" in 6/8 and think he is playing flamenco jazz, and maybe it sounds like flamenco, but it is not a soleá or bulerías. I've worked with many such people. There aren't many who are doing it in a deep way, who know, for example, how to accompany a minera or a rondeña. To do it with profundity you need

\footnotetext{
${ }^{27}$ Corea's "Spain" has the status of a standard in the flamenco jazz repertoire. (The song has no Phrygian passages, but does contain two F-E7b9-type cadences.) Corea is also invoked in song titles such as Alfonso Gamaza's "BuleriChick" and the "Para Chick" on Jazzpaña II.
} 
to study not only Charlie Parker, but also [flamenco guitarist] Sabicas, and the classics of flamenco. ${ }^{28}$

Another Spanish flamenco jazz pianist articulated to me a similar viewpoint, taking as an example the album New York Flamenco Reunion by Spanish jazz drummer Mark Miralta, with sax player Perico Sambeat and others:

It's as if they take the "Real Book" and say, OK, let's play this one por bulerías, with this intro and ending, and they are amazing players, but it doesn't sound flamenco at all, even if they are playing bulerías on top of it. And I have found that these things don't work so well with audiences; you see them fidgeting in their chairs. Those musicians are virtuosos, the level of musicianship is extraordinary, but their audience is mostly other musicians.

At the same time, my informants stressed that such fusions can be judged on their own terms; such aesthetic criteria would have to accommodate the wide variety of hybrids on the jazz end of the flamenco jazz gamut. This essay can merely mention a representative sampling of such projects, many of which are so diverse in form that they cannot simply be plotted on a stylistic continuum.

One idiosyncratic sort of fusion is represented by the collaborations of versatile flamenco singer Diego el Cigala with Cuban pianist Bebo Valdés, in which the vocalist renders jazz-tinged boleros in more or less flamenco style, with his rich, raspy tenor. Other sorts of hybrids have been presented by the eclectic fusion group Ketama, such as their song "Habichuela en Ronnie Scotts [a London jazz club]," a light, minor-key jazz song, in moderate swing rhythm, with lyrics hailing flamenco jazz. ${ }^{29}$

Different sorts of jazz-based crossover have been presented by the aforementioned jazz virtuosos Miralta and Sambeat in productions like New York Flamen-

\footnotetext{
${ }^{28}$ Interviewed, in Spanish, in 1/2016. Guitarist Gerardo Nuñez has voiced similar observations:

"The most jazz musicians have managed is to use the twelve types of bulería rhythm, or to use the Spanish or flamenco scales and do what they can with them. It's like in an American movie when they say 'España', 'música flamenca,' and out come a bunch of Mexicans. There's the odd musician who's been more deeply influenced. Jazz musicians... what they want is to play por bulerias, and they learn the time signature, but to make flamenco music you have to sit down and learn to listen. Knowing how to play guitar accompaniment is essential. ...Using a twelve-beat compás por bulerías like Chick Corea does is another music, that's not flamenco... Paquito D' Rivera and those guys, what they're doing is giving things a Spanish flavor, that's all. You hear the word 'flamenco' and suddenly Chick Corea's 'Spain' starts playing”' (quoted in Llobet 2011:68) ${ }^{29}$ Its lyrics commence, roughly, "A saga began, it seemed impossible, a love story, of two sensitive instruments; one of these expressed itself playing in a jazz club, intoxicating itself every night, playing soleá... flamenco and jazz, a mixture of sounds, different but the same, an invented fable, a unique romance" (on El arte de lo invisible).
} 
co Reunion (2013) and Flamenco Big Band (2007) and the stylistically somewhat similar album Noneto Ibérico led by New York-based Spanish bassist and composer Alexis Cuadrado. Several of the tunes on Miralta's albums are bop standards such as "Moose the Mooche" played in conventional style with no evident pretense to having anything to do with flamenco. A few, such as Monk's "Epistrophy," contain fast palmas clapping in the rhythmic accompaniment. Some feature passages of coloristic flamenco-style singing. In a few instances, such as Cuadrado's "Very Well" and "A Tientos," the listener might not be faulted for wondering what is intended by labeling these items "fandango" and "tientos," respectively. A few other Miralta cuts consist of jazz standards, such as "Bye Bye Blackbird," set to a fast 6/8, somewhat akin to bulerías, in the manner ambivalently commented on above. Also idiosyncratically flamenco-tinged are original compositions such as Sambeat's "Los luchadores no suspiran," described as a soleá, and Guillermo McGill's "Los sueños y el tiempo," which maintain something of the compás of soleares and siguiriyas, respectively, with modern jazz harmonies free of any particular flamenco flavor. ${ }^{30} \mathrm{~A}$ related approach - drawing from flamenco rhythms rather than tonalities - is audible in Miralta's "Evidence" and Cuadrado's "Por la mínima," in which the arrangers freely explore some of the infinite rhythmic possibilities suggested to them by bulerías. "Por la mínima" is particularly intriguing in its layered, minimalist, mutating cross-rhythms; a listener might feel that it could hardly be called a proper bulerías and has little flamenco feeling, but Cuadrado nevertheless found in the bulerías inspiration to create an original and effective piece in the modern jazz idiom.

Finally, in categorizing various flamenco jazz ventures which lie outside the genre's mainstream, one could mention various idiosyncratic productions which do not lend themselves to being plotted on a linear jazz-to-flamenco continuum and whose sui generis approaches have not been widely adopted. Exemplary in this respect is much of the music of eclectic guitarist Chema Vilchez, who uses flamenco and jazz chords to build a thoroughly personal harmonic language, largely eschewing the sorts of familiar directionality that would be provided either by cycle 4 progressions or familiar Phrygian cadences.

FEATURES OF A MAINSTREAM FLAMENCO JAZZ

Much of the richness of the flamenco jazz scene lies in its sheer diversity, including the variety of productions which can be said to lie on the antipodes of the stylistic spectrum rather than its center. At the same time, with a critical mass of creative performers cultivating the genre for what is now at least two

\footnotetext{
${ }^{30}$ Scores to both songs are presented in Guillermo McGill's Flamenco Jazz Real Book.
} 
decades, it is possible to speak of a mainstream form of the idiom whose stylistic and structural features are amenable to description and analysis. This emergent mainstream is of particular interest insofar as it represents not a mere oil-andwater aggregation of elements from the two source genres but rather a coherent new musical language. At times, even within a single given song, the prevailing style may incline more towards one genre than the other but can nevertheless be seen to partake of a core idiom. Hence, for example, Pedro Ojesto stated of his album Rumbo desconocido, "Each song has a different origin of inspiration, some more jazzistic and others more flamenco, but all are united in the language that the Flamenco Jazz Company has developed, with the baggage that its components contribute, over the years." ${ }^{31}$ As in the previous section, this essay does not attempt to catalog the genre's significant names, dates, and albums, but rather to document its formal attributes. The analysis is organized in terms of parameters of rhythm, harmony, form, and the like, with the caveat that these dimensions are interrelated and cannot adequately be discussed in isolation.

\section{Rhythm/meter/compás}

The use of flamenco's distinctive compás patterns is undoubtedly a fundamental feature of flamenco jazz. A typical flamenco jazz album or stage show might include a few duple-metered tangos and rumbas, one or two items por bulerías, perhaps a laid-back song por soleares or siguiriyas, and one or two songs in $6 / 8$ or $6 / 4$ which might not pretend to follow any particular compás pattern. As mentioned in the previous section, an item labeled "bulerías" might or might not contain flamenco's Phrygian harmonies; further, it might or might not at times reflect the bulerías compás, which, as described earlier, would be distinguished by its characteristic weak downbeat and its occasional but nevertheless distinctive accent on beat three, often in the form of a non-tonic chord which resolves to the tonic on beat 6 or 10, characteristically with a dramatic staccato cierre.

As suggested above, jazz players not grounded in flamenco may be less likely to capture the distinctive feel of the bulerías, sometimes to the disappointment of their collaborators. ${ }^{32}$ Alex Conde described to me his experiences in this regard:

${ }^{31}$ At: http://www.flamencojazzcompany.com/item/rumbo-desconocido/

${ }^{32}$ Such might possibly explain the rhythms in "En el corazón de pescaderías" by jazz trumpeter Jerry Gonzalez y los Piratas del Flamenco. The flamenco guitarist plays a quasi-bulerías accompaniment, while Gonzalez's playing suggests more of a 4/4 feel. Jorge Pardo has also spoken of this phenomenon: "I've seen jazz virtuosos be totally confounded by the challenges of playing in the compás of some palo [les ha costado una barbaridad]. Flamenco is a difficult art, you can't just play it as a lark [como el porompompero]." (In

http://www.laprovincia.es/entrevista/2009/03/19/jorge-pardo-grandes-musicos-han-atascadoflamenco/217340.html) 
Sometimes I feel frustrated, in that every time I find a new musician, I have to teach him the rhythms, the feel, and I'm discovering that it's way more complicated than I thought it was. Even amazing musicians, it takes too long for them to get the hang of it, or they say, "I'm sorry, I just can't do it." So what I'm doing now is writing out absolutely everything, so like you see a flamenco bass chart of my song, it's like playing Shostakovich, it's horrible, but it's the only way, though then they can start to take the paper away and feel it more. But if I write only chords, the way they play it will sound so goofy.

Meanwhile, even players steeped in flamenco-such as Chano Domínguezmay also enjoy departing from the norms of compás in elaborating, permutating, and experimenting with bulerías and other palos. Further, perhaps drawing from their familiarity with palos like siguiriyas, they often set pieces to other additive meters, such as $5 / 8,7 / 8$, or $10 / 8(3+3+2+2){ }^{33}$

What is noticeably rare in flamenco jazz is swing rhythm, that most familiar feature of jazz. Instead, whether in $4 / 4$ rumbas or the hemiola-laden bulerías, duple rather than triple subdivision of the beat prevails (even if a very fast bulerías may approach swing feel). Chano Domínguez, in "Bajamar" (on Hecho a Mano) solos in moderate swing rhythm, but the meter is not 4/4 but the 2-23-3-2 of siguiriyas. Palos such as tangos and rumba could not be played in swing rhythm without losing their character. Occasionally, a song in tangos rhythm may have something of a Latin feel, especially if the pianist momentarily breaks into montuno-type patterns (which are certainly familiar to Spanish jazz players).

\section{Harmony}

The distinctive harmonies of flamenco jazz are at least as significant a characteristic of the genre as are the compás patterns of the popular palos. In general, it may be said that flamenco jazz players exhibit a prodigious fondness for complex modern jazz chordal voicings and patterns. A glance, for example, at the Flamen-

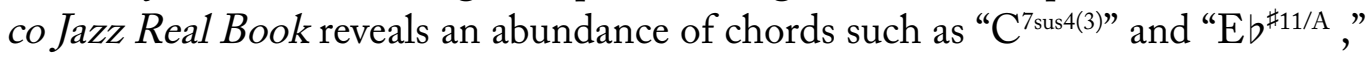
with a conspicuous paucity of familiar ii-V-I progressions. Most flamenco jazz players are eclectic, solidly trained virtuosos of a generation whose musical education started, in some senses, with the modernist sonorities of Wayne Shorter and Chick Corea rather than Coleman Hawkins.

The primary exception to such complex harmonic approaches would lie in renderings of the palos — notably alegrías - which are in common-practice major-

${ }^{33}$ See, e.g., Javier Denis, "E1 vito" (in 5/8), and Alberto Conde Trio, "Judería" (with section in 10/8, from around 1:05), both on Flamenco Jazz. 
key tonalities, wherein the player may consciously strive for a harmonically simple, almost folksy effect. Meanwhile, as we have noted, many flamenco jazz pieces use harmonies essentially typical of modern jazz in general, and derive their flamenco character instead from the use of rhythmic compás patterns. However, it is the use of modernized and elaborated Phrygian harmonies that constitutes a basic and distinctive feature of flamenco jazz, and that certainly has constituted a primary inspiration for most jazz players who have taken up the genre.

As mentioned above, flamenco Phrygian harmonies are in many ways simple, with their limited number of conventional patterns and cadences. However, as noted, these conventions also include forms of altered chords, substitutions, chromaticism, planing effects, and other practices which, if different in structure and logic from counterparts in jazz, nevertheless constitute affinities upon which jazz players have been able to build in cultivating a new syncretic harmonic language.

Flamenco jazz harmony can be seen to employ a variety of elaborating techniques. One basic practice is simply to enrich the standard flamenco chords with non-triadic tones, using conventional jazz extensions and altered notes. Thus, for example, the chords in the cycle 4 turnaround common in tangos (in A Phrygian: $\mathrm{Dm}-\mathrm{G} 7-\mathrm{C}-\mathrm{F}-\mathrm{B} b-\mathrm{A})$ can be given jazz voicings as in Figure $6 \mathrm{~b}$ above, and the first three chords can be treated as a standard ii-V-I in $\mathrm{C}$, with all the adornments and substitutions possible in jazz. A pianist accompanying a singer in a free-rhythmic fandango cante such as granaínas can easily adorn the major-key verse sections with standard jazz (even "cocktail"-type) voicings and flourishes. ${ }^{34}$ Jazz players can also insert standard substitutions in logical places, as shown, for instance, in Figure $5 \mathrm{c}$ above.

In soloing over such chordal passages, even in Phrygian tonality, jazz players can also judiciously interject much of their vocabulary of ready-made lines, such as that shown in Figure 10. Any jazz player or reader of this journal will recognize this as an utterly typical, indeed Parkeresque jazz riff over a Gmin chord, here adapted to Phrygian tonality by concluding on the tonic $\mathrm{A}^{7 b 9}$ chord (instead of perhaps moving to $\mathrm{C} 9$ and $\mathrm{F}$ major, in ii-V-I fashion). While at the fingertips of jazz players, this is precisely the sort of riff that one does not hear from

\footnotetext{
${ }^{34}$ A tasteful example can be heard in Jesús Hernández's "Camino a Mauá" (http://www.jesushernandezmusic.com/?page_id=277). Most fandango forms feature verse sections in major tonality, resolving via pivot chord to the ritornello in Phrygian. Thus, granaínas proceeds roughly: (verse:) D7-G-C-(D7)-G-(A7)-D7-G-C-B7(b9) (ritornello in B Phrygian). Such renderings can also be heard from singer-pianists such as María Toledo and Ariadna Castellanos.
} 
flamenco guitarists improvising in flamenco jazz contexts, as they generally lack background in jazz.

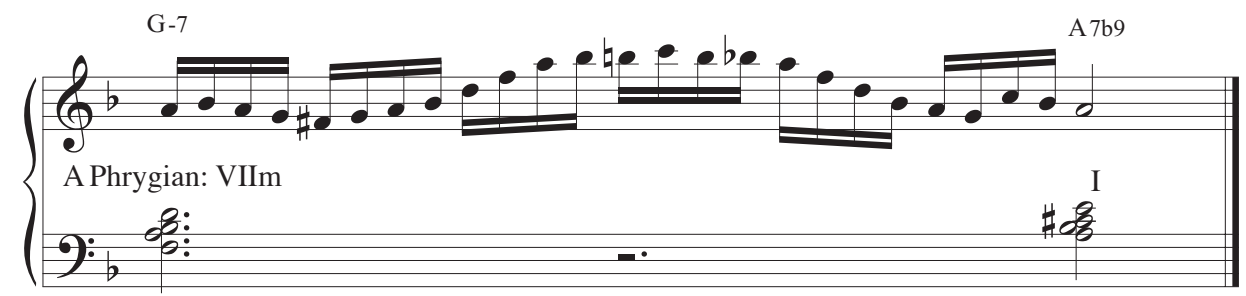

Figure 10. G minor riff in A Phrygian.

Flamenco jazz harmony, like that of jazz itself, abounds in dominant substitutions - in this case, for the Phrygian dominants bII and vii. In Figure 11a (set, like the others, in E Phrygian), the bII (F) is voiced as a standard $9^{\text {th }}$ chord; in $11 b$, it and the tonic are rendered as $7^{b 13+9}$ chords; in 11c, a standard bII dominant is followed by (of all things!) a common-practice V7 (B7) chord, to coloristic effect. ${ }^{35}$
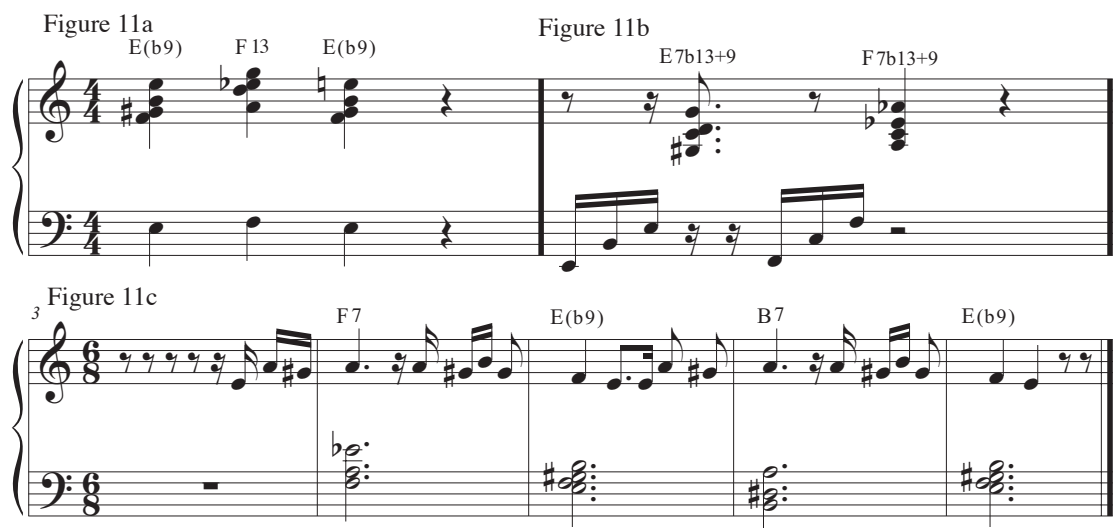

Figure 11. Dominant substitutions.

${ }^{35}$ The voicing in 11a can be heard in Alex Conde, "For Him" (on Jazz \& Claps) at ca. 2:15; 11b is transposed from Chano Domínguez, "Oye como viene" (see footnote 10), at 1:42; and 11c loosely approximates a head theme from Pedro Ojesto's "Soniquete" (on Pedro Ojesto Trio: Quiero), at 1:00 (used with permission). 
Figure 12 shows a similar sort of alternation, in which a scat passage in $G$ Phrygian tonality moves to the subtonic Fm, and thence to a 3-2-1 pattern with jazzistic voicings of $\mathrm{B} b$, passing $\mathrm{E} b$, and $\mathrm{A} b$ chords. ${ }^{36}$
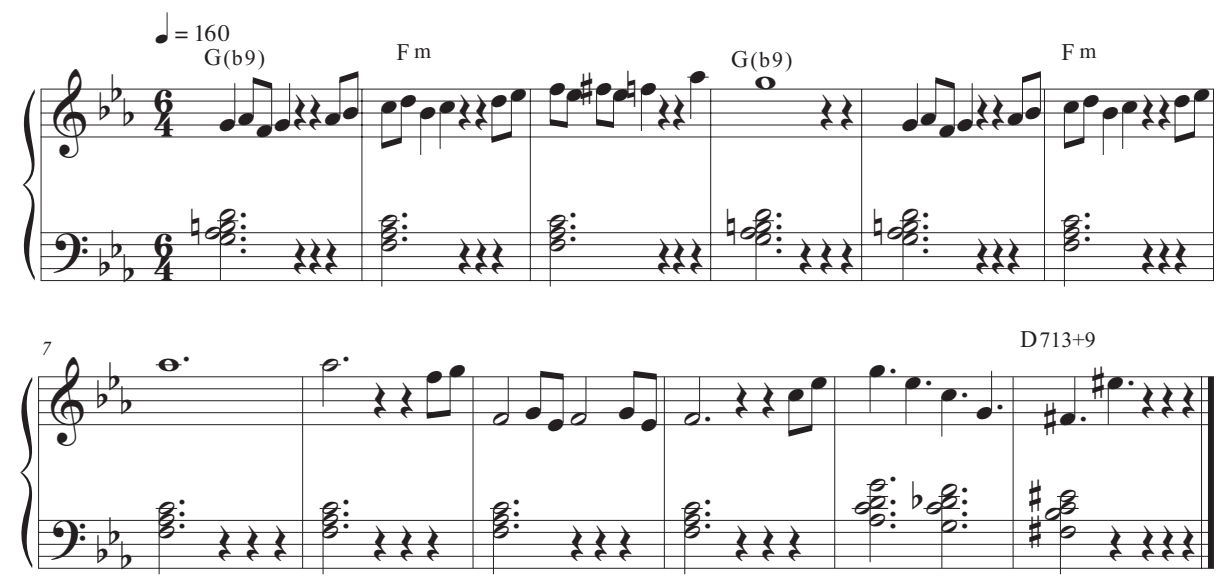

Figure 12. Excerpt of Alex Conde, "Tanguillo for Matthew."

Similar sorts of substitutions can be made for the descending 4-3-2-1 (e.g., Am-G-F-E) progression that constitutes the paradigmatic cadential pattern in flamenco. Figure 13 shows a few typical passages that represent original chord substitutions that nevertheless retain the descending character essential to these points in siguiriyas or soleares; in 13a, these take the form of "Maiden Voyage"type sus 4 chords. ${ }^{37}$
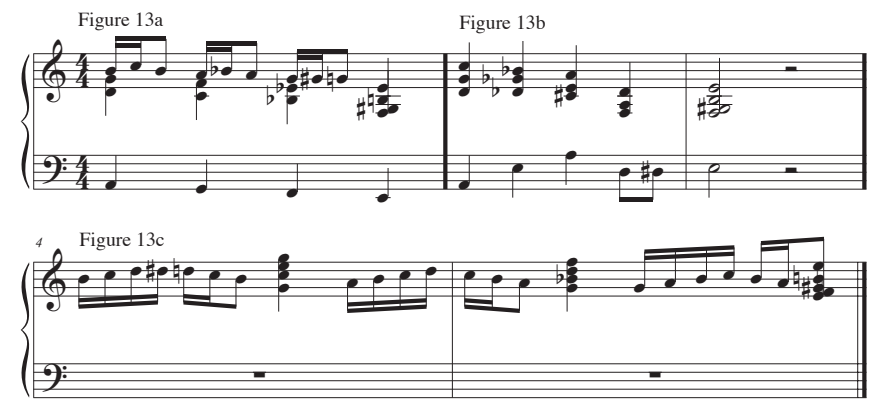

Figure 13. Substitutions in descending patterns.

${ }^{36}$ Alex Conde, “Tanguillo for Matthew," on Jazz \& Claps, at 1:08. Used by permission. The chord notations are schematic rather than indicative of performance.

${ }^{37}$ In soleares, for example, the descent appears in the second compás of the cambio, roughly; /E E F / - - / G7 - - / C - / Am G F / - - / F E F / E - - / 
The Phrygian tonic chord itself can be altered and enriched, including with quartal harmonies popularized by McCoy Tyner and Chick Corea, as shown in the first chord in Figure 14a (on A Phrygian). The subsequent chord is suggestive both of Phrygian tonality and the diminished scale (A-B b-C-D b-Eb-E etc.), which accords easily with flamenco Phrygian tonality in its use of the flat second degree, both third degrees, and the flat fifth degree, which, as noted above, occurs often enough in flamenco. A soloist can retain something of Phrygian flavor with diminished lines like that shown in $14 \mathrm{~b} .^{38}$

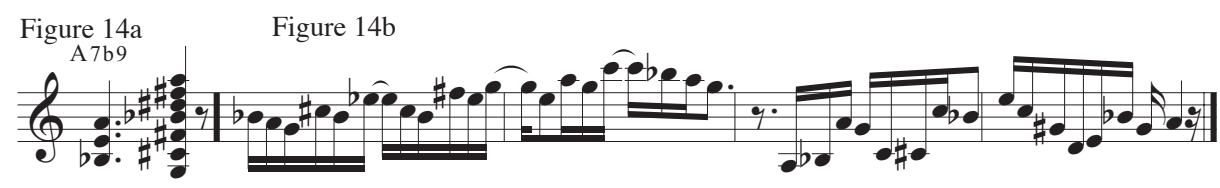

Figure 14. Use of diminished scale.

In flamenco jazz harmony, the single most recurrent, fundamental, and characteristic entity is the $\mathrm{F}-\mathrm{E}^{7 b_{9}}$-type cadence. In flamenco, of course, this occurs as a bII-I cadence on the Phrygian tonic (here, E). This cadence, naturally, can also occur in common-practice (and mainstream jazz) harmony; in A minor, with these $\mathrm{F}$-E chords, it would be $\mathrm{VI}-\mathrm{V}^{7 \mathrm{~b}}$; in $\mathrm{C}$ major, it could precede a vi (Am) chord, that is, IV-III ${ }^{b^{b}}$-vi; and in F major, it could lead to a iii chord: I-VII ${ }^{\text {bq }}$-iii. The typical flamenco jazz score is peppered with such $\mathrm{F}-\mathrm{E}^{7 \mathrm{~b} 9}$-type cadences, often in ways that deliberately exploit the potential ambiguity of their function, while providing the characteristic flamenco flavor. That is, the two-chord cadence is often deployed in a manner that might be heard as a cadence on the Phrygian tonic, or (on different scale degrees) as a modulatory cadence on a different Phrygian tonic, or in one of the aforementioned common-practice functions. A typical example is the first theme of Pedro Ojesto's "Cai," schematized in Figure 15, which presents a passing ii- $\mathrm{V}$-I cadence on $\mathrm{E} b$, a passing ii$\mathrm{V}$ - $\mathrm{i}$ cadence on $\mathrm{Cmin}$, and then a full $\mathrm{Ab}-\mathrm{G}^{7 b 9}$ cadence; the latter, although functionally ambiguous, is likely to be heard as a Phrygian bII-I cadence because it does not lead to a Cmin, it marks the end of the phrase, and it is preceded by a dramatic 16th-note cadential remate phrase typical of bII-I cadences, especially

${ }^{38}$ A good example of this approach is in Alfonso Gamaza's song "Bulerichick," whose head appears in the Flamenco Jazz Real Book. While the song is not commercially recorded, a fine rendering of it is audible at: https://www.youtube.com/watch?v=xemeacp5AxM. The solo by Miguel Ângel López-one might say, yet another hot flamenco jazz pianist—effectively illustrates the use of the diminished scale. 
in bulerías. Often, the tonicity of the $7 b 9$ chord is firmly established by using it as the basis for a vamp.

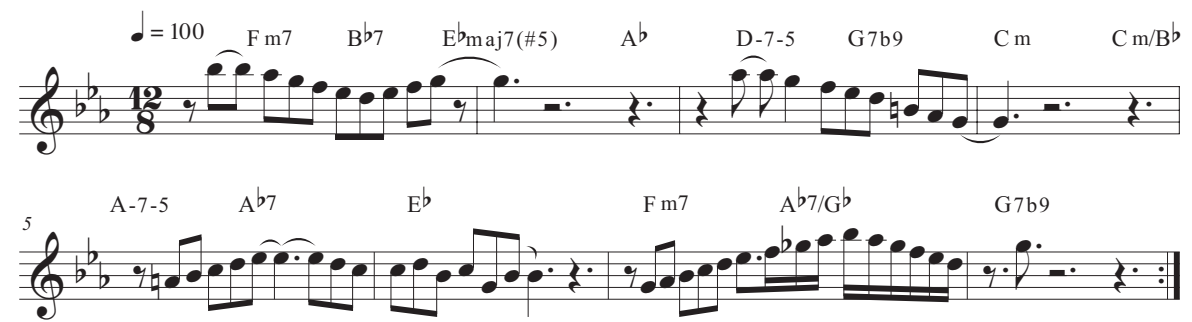

Figure 15. Pedro Ojesto, "Cai," first theme (used with permission).

"Cai," like many, and perhaps even most, flamenco jazz pieces, also goes on to make use of the device we noted in reference to modern flamenco, namely, the modulation (or leap) from one Phrygian tonic to another.

As indicated here, flamenco jazz harmony can be seen to incorporate various elements from modern and mainstream jazz and from traditional and modern flamenco. Some elements of flamenco jazz harmony are best seen as extensions or elaborations of practices and entities already present, or at least latent, in flamenco itself, such as particular altered chords or modulatory conventions. Hence, as cultivated since the 1990s by gifted virtuosos steeped in both musics, flamenco jazz harmony has acquired its own coherence, conventions, and character, such that it has become more than a mere aggregation of discrete and insoluble elements.

Much flamenco jazz foregrounds improvised soloing over chord changes, often in variants of head-solos-head format discussed in the next section; in this sense it naturally resembles jazz. Similarly, as in jazz most of this soloing takes the form of single-note melodies. As noted above, a jazz player may be able to adapt some of his or her ready-made phraseology to the Phrygian harmonies and can certainly give full rein to a modern-jazz style treatment, with artful combination of diatonic and "outside" passages. However, standard ii-V-I riffs may be of limited use, as those progressions may occur only occasionally, and blues riffs and pentatonics, if not outright incompatible with the harmonic language, do not contribute much to it. Many modern jazz players, of course, are versatile and talented enough that they can improvise comfortably over Phrygian tonalities (such as certainly occur in a few modern jazz songs, such as Wayne Shorter's "Sweet Pea"). While it might take some exposure, time, and effort for a jazz player to develop a satisfactory feel for the bulerías compás, Joe Farrell does not 
need to have been raised in a Gypsy cave in Granada in order to solo with great flair over the 6/8 E-F-G-F-E vamp in Chick Corea's "La fiesta." Conversely, as I shall discuss later, flamenco guitarists would be quite stymied by a typical flamenco jazz lead sheet unless they have some genuine grounding in jazz (which hardly any of them do). The jazz musician is far better equipped than the flamenco guitarist to improvise over the complex harmonies typical of flamenco jazz.

Form

If flamenco jazz has its own harmonic and rhythmic language, its conventions of formal structure also often differ from those of jazz. As is well known, the overwhelming majority of jazz songs adhere to the familiar head-solos-head format, in which the head-whether a Tin Pan Alley tune or an original jazz composition-comprises a melody with chord changes (often in 32-bar AABA form) over which the solos are then performed. This format certainly occurs in flamenco jazz but, for various reasons, does not necessarily predominate. There is no tradition in Spanish music of improvising solos over popular songs, such as the coplas and cuplés of the early- and mid-twentieth century, and those songs are not part of the flamenco complex at any rate. Thus, there is no inherited repertoire of potential "standards." More useful might be the nuevo flamenco songs composed since the 1970s, many of which are even in conventional 32-bar AABA form; some of these are in fact used for head-solos-head treatment, but most-however effective they may be as songs-have relatively simple and repetitive chord progressions that would provide little substance or interest as bases for jazz improvisation.

The exceptions in this regard would include modern instrumental flamenco compositions such as Paco de Lucía's "Ziryab" and "Convite," which have fairly elaborate chord progressions and are often played in head-solos-head format. ${ }^{39} \mathrm{It}$ is unclear whether de Lucía composed these songs with the intent of providing suitable changes for soloists, or whether he merely composed them as guitar pieces. However, once incorporated into the repertoire of the sextet, they could be improvised over by Pardo and Benavent, and Chano Domínguez could record an entire album-10 de Paco-of such de Lucía songs in flamenco jazz format.

One theoretical option in flamenco jazz would be simply to solo over the standard chord progression in a given palo, such as a soleá (with its I-bII

${ }^{39}$ Hence flamenco guitarist Rubén Díaz posted on YouTube a video of him strumming the chords to "Convite" for several minutes, presumably for soloists to practice over. At:

https://www.youtube.com/watch?v=t8nX5D2tPsU 
oscillation, moving to VI in the cambio), a tango (I-bII oscillation, leading to the cycle 4 turnaround), or a fandango (with its major-key verse sections punctuated by Andalusian cadences). Such an approach, in some form, is occasionally encountered, but is on the whole rare, probably because these chord progressions in themselves do not provide much harmonic interest for the soloist or listener. ${ }^{40}$ However, in an up-tempo bulerías (or 6/8 song like "La fiesta"), a simple I-bIIIII-bII-I vamp can certainly serve as a satisfactory vehicle for soloing. For that matter, one informal approach to (not) structuring a song would be for a pianist, for example, to play some sort of "head" (which could be essentially a falseta or two) and then freely jam in bulerías compás, as in Figure 17 below.

On the opposite end of the compositional spectrum would be the innumerable flamenco jazz songs with quite elaborate structures, which in some cases do not involve soloing at all. These would include extended, largely through-composed songs for big band, such Perico Sambeat's productions or the two Jazzpaña albums. It would also include multi-sectional, elaborate compositions recorded by Pedro Ojesto (and his Flamenco Jazz Company), Alex Conde, and others. In live performance, these could be extended to accommodate solos, but they also stand as compositions in their own regard, and, as Conde notes, they may also be composed to accompany modern flamenco dance choreographies. ${ }^{41}$

In general, it could be said that flamenco jazz bandleaders, from Pedro Ojesto to Marc Miralta, take particular interest in elaborate compositions, rather than merely attempting to dash off serviceable heads with changes to "blow" over. Accordingly, many songs have complex, multi-sectional heads, but then the solos are taken over the chords of only one of these sections or are taken over a vamp (e.g., a 4-3-2-1 ostinato) that is not part of the head at all. Alex Conde often uses this format, as he explained to me:

I definitely think in sections when I compose, but I find that they don't work well for soloing in flamenco. You can do it, but it's not what I'm

\footnotetext{
${ }^{40}$ An example would be Renaud García-Fons's five-stringed bass improvisation (though not really in jazz style) over the fandango chord changes, on "Un amor real," on Jazzpaña II. In "Soleá blues" (on Hecho a mano), Chano Domínguez effectively extends the soleá into three-phrase blues form, moving to the subdominant in the second phrase and presenting the cambio in the third. Domínguez includes the score to this song in his pedagogical book Flamenco Jazz (p. 43), but he bars the notation in an idiosyncratic manner, placing the accented beats $(3,6,8$, and 10$)$ at the beginning of the $3 / 4$ and $2 / 4$ measures, presumably intending this format to be more intelligible to non-flamenco players. See footnote 16.

${ }^{41}$ As Conde explained to me, such was the intent with the largely through-composed songs on the album Barrio de Carmen, while the songs on Jazz \& Claps are performed more as showcases for his solos. Some of Pedro Ojesto's recordings do not include solos, but the scores, as included in the Flamenco Jazz Real Book, do indicate where solos should be taken.
} 
looking for. It works better for me to solo over small sections; it's more flamenco, more traditional, so I may start the song with ABCDE sections, but then I use just a small section, very easy for the ear, to improvise. For example, if I play Coltrane changes over a bulerías, it just doesn't work, and it's not because I'm playing the wrong notes, it's that the tone is not right for flamenco. Four chords, or two chords--it works way better, then you just blow over the rhythmic stuff.

I asked him about his song "JPG," with its three-section (ABC) head; on his record Jazz \& Claps, he solos over the changes to all three, but a YouTube posting of a live concert shows him soloing only over the A section:

Yes, that might have been. Before we go on stage, we're like, so how shall we do the form of the solos? Eventually, we realized that the audience liked it more when we just stay in the A section. Or maybe we can use the $\mathrm{B}$ and $\mathrm{C}$ sections as an outro to the solo. So I try to listen to the audience, to see what will work.

Pedro Ojesto offered his own explanation for the use of varied forms:

In jazz there's a head (tema) and then improvisation over it. In flamenco what's more normal is a succession of falsetas, telling a sort of story. U1timately I try to combine these two approaches, even within a single te$\mathrm{ma}^{42}$

Another reason for using different changes for solos than are in the head may be that the latter might lack harmonic interest. Such might be the case with Domínguez's "Retaila," a popular bulerías recorded with guitarist Tomatito (on Hecho a mano). The "head" to this song could be regarded as a series of four falsetas (with a coda) which, though colorful, mostly sit on the Phrygian tonic; as indicated in the score in the Flamenco Jazz Real Book, the solos are to be taken on an entirely different set of changes, which, in typical style, move about between different Phrygian tonics.

The practice of using different changes for the solos than for the head is, of course, atypical of straight-ahead jazz, though it is not unheard of in modern jazz; Chick Corea's "La fiesta" is a relevant example, and other instances could be found in Latin jazz (such as Alberto Socarras' "Masabi"), where the solo might be taken over a simple chordal ostinato (a montuno). ${ }^{43}$

${ }^{42}$ In Trancoso 2011:841.

${ }^{43}$ I thank my colleague Ben Bierman for pointing this song out to me. While on the subject of Latin jazz, it is worth mentioning that the sort of synthesis involved in that genre is qualitatively different from that in flamenco jazz. The essence of Latin jazz is the use of Latin (Afro-Cuban) 
The structures of the heads themselves vary. Many feature intricate lines played in unison by pianist, guitarist, and/or horn player. Harmonically, some may alternate an ostinato/vamp section, with a chordal pattern in the manner of jazz tunes like "Moanin'," “Well You Needn't," or “Night in Tunisia." The latter two songs themselves pop up in flamenco jazz contexts, as do a few other standards—such as "Nardis" and the workhorse "Spain"-which have passages compatible with flamenco harmonies. While flamenco jazz continues to lack a canonic repertoire of "standards," Guillermo McGill's aforementioned compilation, Flamenco Jazz Real Book, represents a step toward establishing such a body of songs, which are at once engaging as compositions and suitable vehicles for soloing over.

\section{INSTRUMENTS AND THEIR IDIOMS}

Flamenco as an instrumental idiom has been inextricably associated with a single instrument-the guitar- to an extent that is quite unusual among major world music genres. As noted above, many basic features of flamenco harmonysuch as the non-triadic tones in the chordal vocabulary-derive directly from guitar idiosyncrasies (especially the use of open strings). Palos such as granaínas and tarantas derive their character as much from the distinctive guitar sonorities as from the melodies of their verse sections; the particular strumming patterns in palos like bulerías and the tarantas conclusion are structural rather than incidental elements, and the staccato cierres in tangos, bulerías, and other cantes are impossible to duplicate on other instruments. As an instrumental idiom, much of flamenco as a style is also based specifically on guitar techniques, including forms of strumming, arpeggio, and alzapúa patterns.

Nevertheless, since the 1970s flamenco has come to incorporate other instruments in various forms and contexts. The cajón, after being introduced by de Lucía in that decade, has become a standard element in conventional flamenco performances. Moreover, nuevo flamenco songs are frequently performed by an ensemble including bass and sometimes flute. Finally, while piano will never replace guitar in primacy, it has become accepted in its own circles as a legitimate vehicle for flamenco, even if much of its style is fundamentally imitative of guitar.

rhythms; while there may be a greater use of simple chordal ostinatos (montunos) for soloing, the harmonic language and even much of the repertoire are shared with jazz per se. Flamenco jazz, by contrast, involves an entirely distinct tonality and the unique metrical entities of palos like bulerías. 
In flamenco jazz, this instrumental diversity has been intensified, and indeed the guitar has been largely displaced by the piano as the most characteristic instrument.

\section{The Piano}

The use of the keyboard in stylized renderings of Spanish vernacular music has a venerable history, encompassing the $18^{\text {th }}$-century salon fandangos of Antonio Soler and others, and piano versions of flamenco cantes in zarzuelas in the decades around 1900. Cultivation of piano as a vehicle for instrumental flamenco began in earnest in the 1980s, especially as a new generation of conservatory-trained pianists turned their attention to their nation's richest musical resource. While the piano has made few inroads into the core flamenco contexts (especially all-night voice-and-guitar concerts in Andalusian towns), it has established its own performance milieus and gained a certain sort of legitimacy, complete with well-recognized performers, pedagogical literature, and academic studies (especially Trancoso's 2011 dissertation of 1009 pages). Much of flamenco piano style, as mentioned, is clearly imitative of the guitar techniques and sonorities that are central to the idiom, but pianists have also extended that general style to accommodate features idiomatic to the keyboard.

If the piano has gained a certain sort of acceptance in flamenco as a whole, it is the instrument par excellence of flamenco jazz. As the ranks of solidly trained Spanish jazz pianists have exponentially increased, many have found cultivation of flamenco jazz attractive and even commercially remunerative. The piano also lends itself relatively easily to jazz-style soloing, with its basic technique of righthand single-note runs and left-hand comping. Further, the first generation of flamenco jazz pianists could find ready models in the improvisations of Chick Corea in songs like "La fiesta" and "The Jester and the Tyrant" (with its Andalusian la-sol-fa-mi ostinato).

The seminal figures in this generation were Pedro Ojesto (b. 1953) and especially Chano Domínguez. Both grew up solidly grounded in flamenco, with flamenco guitar being Domínguez's first instrument. As the latter attests, much of his style represents adaptations of guitar techniques to the piano, although in other ways he is very much a jazz player, quite overtly inspired by Corea. Domínguez describes the guitar-piano relation insightfully:

Flamenco piano at least begins with a projection of the guitar onto the piano. The language of flamenco starts with voice and guitar, those are the main references. There are musicians who play flamenco on different instruments. At first, one adapts guitar falsetas, but then you can play 
more pianistic things, you don't need guitar. And in the case of flamenco and jazz, you don't always need to copy the guitar, you can express yourself through your own instrument. There aren't specific instruments for flamenco, or any other music, it's the musician that can make it sound flamenco. ${ }^{44}$

Alex Conde voiced a similar perspective:

Piano really isn't an instrument for flamenco. You can't do what the guitar does. So there was a time of my life when I was trying to play piano like a guitar. Now I'm moving on from that. I'm trying to play it like a piano. The guitar is, like, a very small place on the piano. There are so many more options on the piano.

For flamenco jazz pianist Diego Amador (b. 1973) — a scion of a prominent Gypsy flamenco family - the guitar remains paramount: "They call me a pianist, but I'm a guitarist that plays piano; I close my eyes and I'm playing guitar." ${ }^{45}$

As mentioned, flamenco jazz as played on piano tends, like jazz piano, to favor right-hand improvised runs with left-hand comping. At the same time, pianists do their best to imitate staccato cierre strums and the rhythmically driving alzapúa patterns. Figure 16a shows a typical alzapúa guitar pattern played in A Phrygian. Figure 16b presents a piano riff-the likes of which have become an absolute cliché in flamenco piano-which imitates the feel of alzapúa in its repetitive rhythmic character. Figure 16c (in E Phrygian) shows a typical 4-bar alzapúa pattern as played on guitar (in this case, with a capo on the seventh fret); $16 \mathrm{~d}$ shows how Chano Domínguez might vary this sort of pattern (as can be heard on his popular "Yo quiero caminar" at 0.40). Such alzapúa-type patterns typically occur at the tail end of phrases; anyone familiar with mainstream flamenco would easily recognize a phrase such as $16 \mathrm{~d}$ as a substitution for the standard alzapúa riff.

\footnotetext{
${ }^{44}$ Interviewed in deflamenco.com, $1 / 17 / 2003$, at: http://www.deflamenco.com/revista/entrevistas/entrevista-a-chano-dominguez-1.html

${ }^{45}$ Interviewed, at: https://www.youtube.com/watch?v=xzo6z6r3F1Q. Amador is somewhat unusual among flamenco jazz pianists in being self-taught and musically illiterate. His playing, however, reflects an obvious understanding of modern jazz harmony.
} 

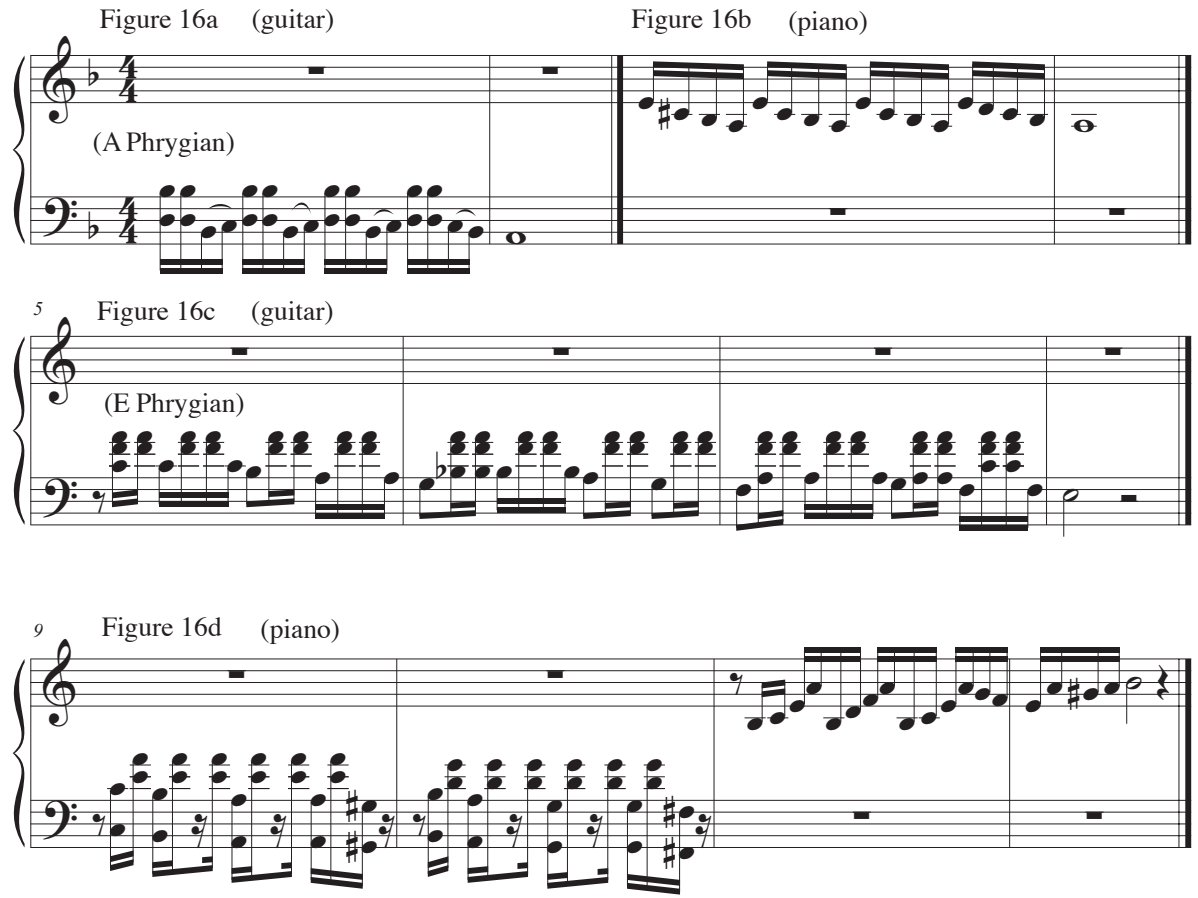

Figure 16a. guitar alzapúa (2mm, in A); 16b. alzapúa-like piano riff (2mm); 16c. guitar alzapúa (4mm, in E); 16d. Chano Domínguez piano alzapúa-like pattern (4mm).

Oddly, flamenco jazz pianists, perhaps because of the ease of adapting such guitaristic techniques to different keys and contexts, have introduced more of them into their playing than have guitarists in flamenco jazz projects, who largely restrict themselves to single-note runs.

\section{The Guitar}

If piano has become the preferred instrument of flamenco jazz, guitar-the king of flamenco itself-has struggled to find a place in the idiom. The main problem has been that while Spain has produced an abundance of jazz pianists who can readily adapt their talents to flamenco jazz, there has been a surprising dearth of Iberian jazz guitarists. Instead, there are legions of virtuoso flamenco guitarists, who, while gifted in their ways, are almost without exception musically illiterate, untrained in jazz, and hence unable to contribute in the same way as 
pianists. ${ }^{46}$ As mentioned, many flamenco jazz productions do manage to integrate flamenco guitarists in certain contexts, although these are often coloristic rather than structural insertions and occur in points-such as Phrygian or harmonically static passages - that do not challenge the guitarists' skill set. When such guitarists do take solos, they tend to follow chord changes in somewhat diatonic, idiosyncratic manners devoid of jazz phrasings. Moreover, such guitarists tend to restrict their technique to single-note picado melodies rather than enriching their solos with other textures such as arpeggio and alzapúa.

We have discussed Paco de Lucía's relation to jazz and his own admitted lack of facility in that idiom. A few other flamenco guitarists, such as Tomatito and Josemi Carmona, reflect in some of their collaborative ventures a stronger familiarity with ii-V-I phrasings and the like; similarly, as noted, Niño Josele has worked out credible arrangements of Bill Evans songs, but none of these artists appears to have cultivated a genuine fluency in improvising solos over jazzinformed changes. For his part, versatile virtuoso Gerardo Nuñez has been featured in some flamenco jazz productions-especially the Jazzpaña albumsbut he is not, by his own admission, a jazz player, and he contributed solos to those arrangements only in selected passages. Marcos Teira stands out as perhaps the only guitarist with a public presence who, steeped in both Sabicas and George Benson, has worked out convincing arrangements of jazz standards rich with the range of flamenco guitar techniques. ${ }^{47} \mathrm{He}$ explained to me:

I've tried to work with the technical language of the guitar, the arpeggios and rasgueos, and so on, but it's very difficult. Flamenco technique is quite demanding that way. In order to compose a falseta or an arrangement, you have to work hard, and then to improvise using such techniques, it's even harder, the guitar is like a handicap. And so there haven't been many guitarists who have tried to go beyond picado in improvising solos.

A more logistical problem has involved the challenge of working such a soft instrument as the acoustic guitar into the fabric of a combo. In live performance, even when heavily miked, the nylon-stringed, finger-plucked flamenco guitar is easily overwhelmed by other instruments, unless the percussionist barely touches his instrument and the pianist lays out altogether (which Michel Camilo certainly did not do in his duets with Tomatito). ${ }^{48}$

${ }^{46}$ Django Reinhardt, of course, famously showed that a musical illiterate could indeed play jazz, although he was of course steeped in that idiom, and further, the prevailing harmonies in his music were considerably simpler than those of modern jazz and flamenco jazz.

${ }^{47}$ Teira is the author of a nicely crafted pedagogical guide, Flamenco Jazz Translations (2013), with a CD containing his flamenco settings of five jazz standards.

${ }^{48} \mathrm{Jaco}$ Abel has expertly adapted flamenco to electric guitar and has also pursued various fusion projects; some of these incline more toward rock than jazz, while his recording of "Nardis" has no 


\section{Other Instruments}

Wind instruments had no place in flamenco until the 1970s, when Paco de Lucía incorporated flute and sax player Jorge Pardo into his sextet and associated recordings. Pardo, a jazz player by background, soon found his career consisting mostly of flamenco and flamenco jazz projects with de Lucía and others. Flute and sax are unable to carry a song the way guitar or piano can, but the versatile Pardo illustrated how they can perform effective solos and interludes. In Pardo's wake, several other wind players have become active in the field. A typical format is for soprano sax and guitar (or piano) to play an intricate head, and then each take solos over changes. An eclectic flamenco guitarist such as Adam del Monte (on Así lo siento yo) can lend his recordings a lively jazz flavor through incorporating a sax player in such a manner. A particularly felicitous approach is that of the young Antonio Lizana, who is at once a fine flamenco vocalist (in a style redolent of Camarón de la Isla) and a virtuoso, conservatory-trained jazz saxophonist. Lizano's music is diverse, but a typical format is for his songs to consist of nuevo flamenco-type entities in which he alternates singing the largely precomposed "song" sections over modern flamenco harmonies (provided on piano or guitar, with bass and/or percussion) with improvised "blowing" on soprano or tenor sax, perhaps over a different set of chord changes.

From the latter 1970s, the pre-composed and somewhat pop-oriented nuevo flamenco songs of de Lucía (such as "Como el agua") featured bass accompaniment by Carles Benavent (b. 1954), a gifted and eclectic jazz musician. Like Pardo (with whom he often collaborates), Benavent has set the standard and effectively defined the style for his instrument in flamenco jazz. He generally flat-picks a five-string electric bass (with a high $\mathrm{C}$ in place of a low $\mathrm{B}$ ); in the upper register, especially in solos, he freely plays guitaristic diads, triads, and fast runs. (Like Domínguez and Nuñez, he has also had to contend with a serious hand injury.) Benavent has been a fecund recording and concert artist, and in this digital era, he, like others, is also able to supply recorded tracks via the internet, contributing in that fashion, for example, lively accompaniment and solos to del Monte's aforementioned album (the rest of which was recorded in California). With inspiration of Benavent and the late Alfonso Gamaza, flamenco bass playing has become a recognized idiom, complete-like flamenco piano-with its own pedagogical literature (e.g., Martos 2008).

In similar fashion, drum set has become standard in flamenco jazz combos, and drummers have developed their own characteristic ways of accompanying

flamenco elements. Jazz guitarist Lenny Breau also played flamenco guitar at an intermediate level but did not cultivate any particular fusion of jazz with flamenco. 
bulerías and other palos. Particularly influential have been Guillermo McGill and Marc Miralta, both of whom are also composers, arrangers, bandleaders, and pedagogues. (McGill, author of several flamenco jazz songs, is also the compiler of the aforementioned Flamenco Jazz Real Book.)

SOLO ANALYSIS

It may be instructive at this point to examine a representative improvised solo. As mentioned, solos may occur over various changes, including those of a precomposed chord cycle or a recurring vamp. In this case, virtuoso pianist Alex Conde performs an informal romp in bulerías in $\mathrm{C}$ Phrygian without bass accompaniment or any fixed set of changes. (The audio is posted on YouTube and Vimeo. ${ }^{49}$ ) After a head (not notated), the solo begins at roughly 1:30, moving immediately to the minor vii chord ( $\mathrm{B} b$ minor), which recurs as the primary dominant substitution or lower neighbor throughout the solo. At bar three, there is a characteristic bulerías accent on beat three with a coloristic GAb-c triad. A guitaristic left-hand figure (imitating an alzapúa pattern) moves again to the $\mathrm{B} b$ minor, and then, in bar 6 , to an "outside" excursion through $\mathrm{B}$ minor and, implicitly, $\mathrm{C} \#$ minor, to the tonic. From the end of bar 8, chromatic motion through $\mathrm{B}$ minor, $\mathrm{B} b$ minor, and $\mathrm{C}$ minor is again suggested and gives way to an ascending set of arpeggiated fourths. Bar 11 returns to the tonic but then proceeds through a diminished-scale ascending run to $\mathrm{G}$ minor, $\mathrm{B} b$ minor, and harmonically ambiguous quartal comping. Another chromatic run sets up further tension, resolving dramatically in bulerías fashion on beat 10 of the last bar. The solo in general could be said to be in typical modern jazz style, with right-hand runs and economic left-hand comping; the moves through remote, "outside" chord areas flow smoothly and lend variety to the otherwise limited chordal resources of the Phrygian tonality. The bulerías rhythm is obscured much of the time, but is indicated on specific occasions.

\footnotetext{
${ }^{49}$ At the YouTube and Vimeo sites accompanying this article; see footnote 13. The recording was an informal affair and the audio quality is accordingly not at professional standards. However, the solo, aside from being played with great flair, nicely illustrates various points made in this article. My transcription does not pretend to be entirely accurate. I thank Conde for permission to present it here.
} 

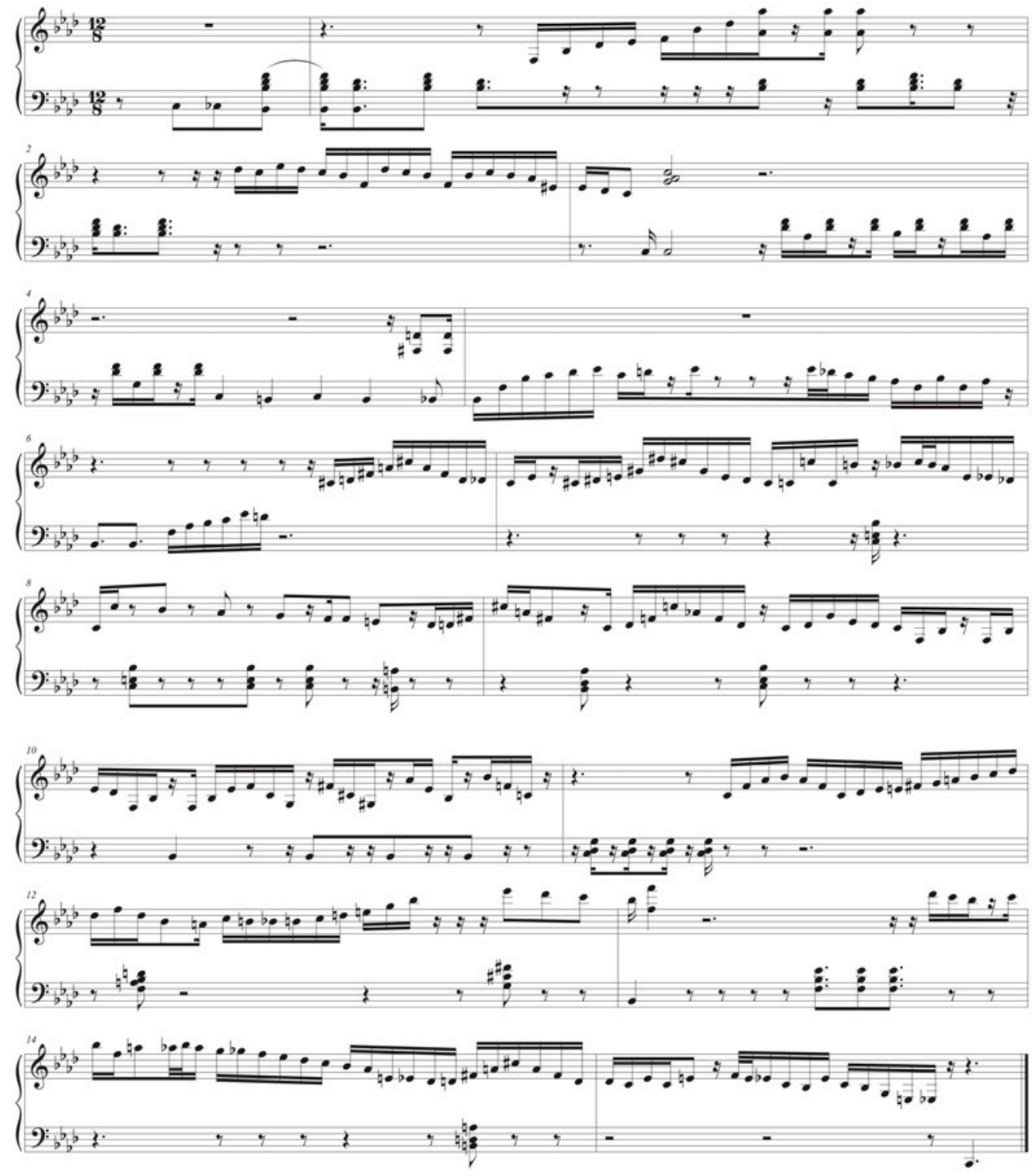

Figure 17. Alex Conde, piano solo in bulerías.

\section{CONCLUSIONS}

In 2011, Pedro Ojesto offered a rather sober assessment of the flamenco jazz scene:

I would say that flamenco jazz has yet to evolve much. Why? Because there aren't many jazz musicians who know how to play por soleá, nor 
many flamenco musicians who can really swing, and who know how to read a score. It may yet happen, but there still isn't much. ${ }^{50}$

A more favorable assessment of the scene-especially after the passing of six years--could claim flamenco jazz as a particularly dynamic development in a jazz world otherwise characterized as much by fragmentation and lack of direction as abundance of talent. To be sure, flamenco jazz has been spearheaded and indeed dominated by a small core of trendsetters-especially, perhaps, Domínguez, Pardo, Benavent, Ojesto, Sambeat, McGill, Conde, and Miralta. Moreover, given Spain's financial slump and the finite global market for jazz, the flamenco jazz scene, even more than that of jazz in general, cannot by itself support many full-time musicians, however gifted they may be. ${ }^{51}$ And yet, each few years brings a handful of new contributors as well as CDs, popular YouTube posts, pedagogical materials, and performance venues. Most important has been the coalescence of a coherent style that-like a creole language-has become much more than a combination of undigested elements from its two sources. Chano Domínguez explains:

Lots of people ask me where is the flamenco or the jazz in my music, and I don't know what to say because my music intertwines them together. We're playing a bulerías, but in the musical form of a blues, or I'm accompanying a vocal malagueña, but the harmony is more extensive than what a flamenco guitarist would play as accompaniment. All these things make the language continue to open up and grow. ${ }^{52}$

While this article has shown how the constitutive elements of flamenco jazz can indeed be traced to their origins in one genre or the other, they have been selectively combined and elaborated in such a way as to become inseparable in their new musical context as parts of an interwoven fabric.

Aside from the formal analysis presented in this essay, the flamenco jazz phenomenon certainly has various sorts of socio-musical significance, some aspects of which have been explored by Spanish writers. From one perspective, it reflects the belated flowering of Spanish culture after four decades of stultifying fascist dictatorship. The phenomenon is also conditioned by the intensification of globalization in recent decades, as YouTube and the internet in general enable enthusiasts to enjoy and cultivate the art everywhere from Guatemala to Helsinki.

\footnotetext{
${ }^{50} \mathrm{http} / /$ www.deflamenco.com/revista/entrevistas/entrevista-a-jazz-flamenco-company-pedroojesto-david-cerreduela-jose-miguel-guzman-1.html

${ }^{51}$ Both Chano Domínguez and Alex Conde, after residing on the west coast of the USA, have recently relocated to New York City rather than living in Spain.

${ }^{52}$ In Trancoso 2011:818.
} 
The new hybrid can also be seen as a unique enrichment of jazz in a situation where jazz as a genre has come to comprise, on the one hand, a tired mainstream style some sixty years old, and on the other, a splintered collection of idiosyncratic fusions and personal idioms. Flamenco jazz, it could be said, constitutes one more such fusion, but it may turn out to be a particularly productive and durable one. Finally, the flourishing of the genre illustrates how the global style pool can be enriched by new and dynamic hybrids, which to some extent offset the disappearance of older forms under the impact of modernity.

\section{BIBLIOGRAPHY}

Bruckner-Haring, Christa. "Jazz research in Spain."

http://nauxxi.uv.es/wp-content/uploads/2013/11/JF42155-172-Jazz-Researchin-Spain-Bruckner-Haring.pdf

Cleveland, Barry. 2014. "Gypsy Genome Tomatito Reaffirms his Flamenco Essence on Soy flamenco." Guitar Player 48(1): 48 (January).

Domínguez, Chano. 2005. Flamenco jazz: Partituras. Madrid: RGB Arte Visual S.L.

Fernández Fernández, Mar. 2013. "La fusión del jazz-flamenco.” Accessible at: https://www.academia.edu/7582362/La_fusion_del_Jazz_y_del_Flamenco_by_ Mar_Fernández

Fernandez, Lola. 2008. Flamenco al piano [4 volumes: Soleá, Tangos, Bulerías, Alegrías]. Madrid: Acordes Concert.

García, Jorge. "El trazo del jazz en España." n.d. http://www.bne.es/es/Micrositios/Exposiciones/Jazz/resources/img/estud io1.pdf;

García Martínez, José María. 1996. Del fox trot al jazz flamenco: El jazz en España: 1919-1996. Madrid: Alianza Editorial.

García Saleh, Alberto. 2009. "Jorge Pardo: 'Grandes músicos se han atascado en el flamenco'.” Laprovincia.es (Diario de Las Palmas) (March 19). 
Herrero, Germán, 1991. De Jérez a Nueva Orleans: Análisis comparativo del flamenco y del jazz. Granada: Editorial Don Quijote.

Iglesias, Ivan. 2005. "La hibridación musical en España como proyección de identidad nacional orientada al mercado: El jazz-flamenco." Revista de Musicologia 28(1).

Jiménez de Cisneros Puig, Bernat. 2015. Ritmo y compás: Análisis musical del flamenco. Atril Flamenco.com [online].

Lag-Lopez, Nieves. 2006. Estudio comparativo del jazz y el flamenco andaluz: Origenes y evolución. Asociación Procompal.

Llobet, Francisco Javier Bethencourt. 2011. "Rethinking Tradition: Towards an Ethnomusicology of Contemporary Flamenco Guitar.” PhD diss., Newcastle University.

Manuel, Peter. 2006. "Flamenco in Focus: An Analysis of a Performance of Soleares." In Analytical Studies in World Music, edited by Michael Tenzer, pp. 92-119. New York: Oxford University Press.

—. 1989. "Modal Harmony in Andalusian, Eastern European, and Turkish Syncretic Musics." Yearbook for Traditional Musics 21: 70-94.

—. 1986. "Evolution and Structure in Flamenco Harmony." Current Musicology 42: 46-57.

Martos, Mariano. 2008. Flamenco Bass Method. Madrid: RGB Arte Visual.

Pérez Custodio, Diana. 2005. Paco de Lucía: La evolución del flamenco a través de sus rumbas. Cádiz: Universidad de Cádiz.

Salinas Rodriguez, Jose. 1994. Jazz, flamenco, tango: Las orillas de un ancho río. Madrid: Editorial Catriel.

Sevilla, Paco. 1995. Paco de Lucía: A New Tradition for the Flamenco Guitar. San Diego: Sevilla Press. 
Steingress, Gerhard. 2004. "La hibridación transcultural como clave de la formación del nuevo flamenco (Aspectos histórico-sociológicos, analíticos y comparativos)." TRANS - Revista Transcultural de Música 8 [http://www.sibetrans.com/trans/trans8/steingress.htm].

- 2007. Flamenco postmoderno: Entre tradición y heterodoxia: $U_{n}$ diagnóstico sociomusicológico (escritos 1989-2006). Sevilla: Signatura.

Teira, Marcos. 2013. Flamenco Jazz Translations. Madrid: RGB Arte Visual.

Téllez, Juan José. 2003. Paco de Lucía en vivo. Madrid: Plaza Abierta.

Torijano, Carlos. 2010. Piano Flamenco Method (Book/DVD Set; 2 volumes). RGB Arte Visual.

Trancoso González, Jaime. 2011. "El piano flamenco: Génesis, recorrido diacrónico y análisis musicológico." PhD diss., Universidad de Seville.

Zagalaz, Juan. 2012a. "The Jazz-Flamenco Connection: Chick Corea and Paco de Lucía between 1976 and 1982." Journal of Jazz Studies 8(1).

- 2012b. "Flamenco-Jazz: Una perspectiva analítica de sus orígenes: La obra temprana de Jorge Pardo, 1978-1981." In Las fronteras entre los géneros: Flamenco y otras músicas de tradición oral, ed. José Miguel Díaz Báñez, Francisco Escobar Borrego, and Inmaculada Ventura Molina. Sevilla: Universidad de Sevilla. 


\section{DISCOGRAPHY}

Abel, Jaco. 1998. Gitano cromático.

Amigo, Vicente and El Pele. "El emigrante." 2010. On Tributo flamenco a Don Juan Valderrama. RCA.

Amaya, Remedios. 1998. Me voy contigo. EMI 724349616622.

Camilo, Michel and Tomatito. 2000. Spain. Universal Music 0731456154527.

Conde, Alex. 2013. Barrio de Carmen. Alex Conde.

—. 2011. Jazz \& Claps. Contrasena Records.

Corea, Chick. 1976. My Spanish Heart. Polydor PD-2-9003.

—. 1972. Return to Forever. ECM 78118 21022-4.

Cuadrado, Alexis. 2011. Noneto ibérico. Brooklyn Jazz Underground Records.

de Lucía, Paco. 1990. Zyryab. Polygram Iberica / Philips 8467072.

Domínguez, Chano. 1993 Hecho a mano. Nuba Records NUBA 7759.

—. 10 de Paco. 1994. Milestone MCD 9229-2.

Flamenco Jazz Company (Pedro Ojesto). Rumbo desconocido. Nuba Records / Karonte.

—. 2011. Nikela. Karonte.

Josele, Niño. 2006. Paz. BMG BVCJ-31046.

Ketama. 1993. El Arte de lo invisible. Polygram Iberica Philips 514 817-2.

Mendoza, Vince and Arif Mardin. 1993. Jazzpaña. Atlantic 82539-2.

Miralta, Marc. 2013. Marc Miralta Flamenco Reunion. Karonte / Nuba Records.

—. 2000. New York Flamenco Reunion. Nuevos Medios. 
Nuñez, Gerardo et al. 2000. Jazzpaña II. ACT Music 9284-2 ACT.

Ojesto, Pedro. 2004. Pedro Ojesto Trio: Quiero. Karonte / Nuba Records.

Poveda, Miguel. 1998. Suena flamenco. Harmonia Mundi HMI 987019.

Sambeat, Perico. 2007. Flamenco Big Band. Universal Music 0602517808294.

Various artists. 2007. Flamenco Jazz. Frémaux \& Associés / Nuba Records FA 5143.

Vilchez, Chema. 2011. Tierra de las 2 culturas. World Village Music. WWV 498048 .

\section{ABOUT THE CONTRIBUTOR}

Peter Manuel has researched and published extensively on musics of India, the Caribbean, Spain, and elsewhere. His several books include Caribbean Currents: Caribbean Music from Rumba to Reggae, and Cassette Culture: Popular Music and Technology in North India. An occasional performer of sitar, flamenco guitar, and highland bagpipes, he teaches ethnomusicology at John Jay College and the Graduate Center of the City University of New York. 